\title{
Effects of Land Surface Schemes on WRF-Simulated Geopotential Heights over China in Summer 2003*
}

\author{
XIN-Min ZENG AND B. WANG \\ College of Meteorology and Oceanography, PLA University of Science and Technology, and Key Laboratory for \\ Mesoscale Severe Weather of Ministry of Education, Nanjing University, Nanjing, Jiangsu, China \\ Y. Zhang, Y. Zheng, N. WANG, M. WANG, X. Yi, C. Chen, AND Z. ZHOU \\ Key Laboratory for Mesoscale Severe Weather of Ministry of Education, Nanjing University, Nanjing, Jiangsu, China
}

H. LIU

College of Meteorology and Oceanography, PLA University of Science and Technology, and Key Laboratory for Mesoscale Severe Weather of Ministry of Education, Nanjing University, Nanjing, Jiangsu, China

(Manuscript received 29 December 2014, in final form 27 September 2015)

\begin{abstract}
To quantify and explain effects of different land surface schemes (LSSs) on simulated geopotential height (GPH) fields, we performed simulations over China for the summer of 2003 using 12-member ensembles with the Weather Research and Forecasting (WRF) Model, version 3. The results show that while the model can generally simulate the seasonal and monthly mean GPH patterns, the effects of the LSS choice on simulated GPH fields are substantial, with the LSS-induced differences exceeding $10 \mathrm{gpm}$ over a large area (especially the northwest) of China, which is very large compared with climate anomalies and forecast errors. In terms of the assessment measures for the four LSS ensembles [namely, the five-layer thermal diffusion scheme (SLAB), the Noah LSS (NOAH), the Rapid Update Cycle LSS (RUC), and the Pleim-Xiu LSS (PLEX)] in the WRF, the PLEX ensemble is the best, followed by the NOAH, RUC, and SLAB ensembles. The sensitivity of the simulated 850-hPa GPH is more significant than that of the $500-\mathrm{hPa}$ GPH, with the $500-\mathrm{hPa}$ GPH difference fields generally characterized by two large areas with opposite signs due to the smoothly varying nature of GPHs. LSS-induced GPH sensitivity is found to be higher than the GPH sensitivity induced by atmospheric boundary layer schemes. Moreover, theoretical analyses show that the LSS-induced GPH sensitivity is mainly caused by changes in surface fluxes (in particular, sensible heat flux), which further modify atmospheric temperature and pressure fields. The temperature and pressure fields generally have opposite contributions to changes in the GPH. This study emphasizes the importance of choosing and improving LSSs for simulating seasonal and monthly GPHs using regional climate models.
\end{abstract}

\section{Introduction}

Geopotential height (GPH) is one of the most fundamental variables considered in meteorological and climatological research and applications. Because of its

\footnotetext{
* Supplemental information related to this paper is available at the Journals Online website: http://dx.doi.org/10.1175/JHM-D-14-0239.s1.

Corresponding author address: Dr. Xin-Min Zeng, College of Meteorology and Oceanography, PLA University of Science and Technology, 60 Shuanglong Street, Zhonghuamenwai, Nanjing 211101, Jiangsu, China.

E-mail: zen_xm@yahoo.com
}

close relationship with air pressure, GPH is also an important variable for characterizing general atmospheric circulation. In an earlier work on numerical forecasting, Phillips (1957) proposed a sigma coordinate system in which GPH was used as the dependent variable when depicting general atmospheric circulation from the hydrostatic equation. Following the work of Phillips (1957), several researchers have used GPH as a major variable to assess model performances for weather and climate modeling and prediction. For example, to evaluate the performance of the ensemble prediction system operationally used at the European Centre for MediumRange Weather Forecasts (ECMWF), Chessa and Lalaurette (2001) applied some basic measures of skill 
to a probabilistic forecast of four regimes for the $700-\mathrm{hPa}$ GPH. Moreover, some investigators focused on predicting the 500-hPa GPH [e.g., Zheng and Frederiksen (2007) applied a variance decomposition approach to predict seasonal 500-hPa geopotential height anomalies in the Southern Hemisphere]. Although GPH is not a forecast variable of the atmospheric model in the dynamical seasonal prediction system at the National Centers for Environmental Prediction (NCEP; Kanamitsu 1989), the GPH anomaly is a major quantity in the assessment of general atmospheric circulation patterns in the NCEP Dynamical Seasonal Forecast System 2000 (Kanamitsu et al. 2002) and NCEP Climate Forecast System (Saha et al. 2006). In addition, many investigators have found that the GPH field can be considered as a key predictor, particularly when downscaling regional/local climate. For instance, Yang et al. (2012) suggested that the 2-m maximum and minimum temperatures are closely related with the $850-\mathrm{hPa} \mathrm{GPH}$, which can be considered as a useful predictor for temperatures in China. All of the above-mentioned studies have demonstrated the crucial role of GPH in research and its applications at weather and climate time scales.

The climate over continental China is characterized by its large time-space variability and is closely associated with the general atmospheric circulation, which is commonly shown by the GPH field. For instance, around mid-May the rain belt near the equator suddenly moves northward and merges with the southern China rain belt. Next, the East Asian summer monsoon advances northward and northeastward in a distinct stepwise manner (Ding and Chan 2005). This sudden onset of the monsoon season in the South China Sea has been well documented by several researchers based on largescale wind, GPH, rainfall, and OLR patterns (Lau and Yang 1997; Wang and Lin 2002) and can be explained by changes in the temperature gradient (as well as the GPH gradient) over continental China (Wu and Wang 2001; Zhang et al. 2004). In addition, numerical studies of the monsoon system, which contain some major synoptic systems over China (e.g., the western Pacific subtropical high, as characterized by the $500-\mathrm{hPa}$ GPH field), were also carried out (e.g., Chen et al. 2010).

Currently, general circulation models (GCMs) are very useful for simulating and predicting large-scale general circulation. However, when used for climate research and applications at regional scales, GCMs are unable to capture some regional features (e.g., complex topography and local circulation dynamics) and have large computational costs with greater spatial resolution (e.g., Dickinson et al. 1989; Giorgi and Mearns 1999; Argüeso et al. 2011). To partially overcome these deficiencies, regional climate models (RCMs) have been widely employed for climate simulation and prediction during the last three decades (e.g., Giorgi and Mearns 1999; Chen and Xie 2012). Thus, when assessing RCM simulations over China, two questions should be asked: 1) How well do the commonly used RCMs reproduce the GPH field over continental China? and 2) To what extent is the simulated GPH field sensitive to different physical parameterizations?

The first question might be important to model users who are interested in the overall performance of stateof-the-art RCMs (e.g., Wang et al. 2004; Findell et al. 2006; Seneviratne et al. 2006; Walther et al. 2013; Akkermans et al. 2014) and is an important issue regarding the application of forecast GPH fields, as stated above. Unlike modeled precipitation and temperature sensitivities to physical options, which have drawn significant attention (e.g., Giorgi 1991; Argüeso et al. 2011), the sensitivities of GPH fields to different physical parameterizations have rarely been investigated by focusing on GPHs. In addition, the second question is of interest because the uncertainty of the simulated GPH field can be shown because of the complexity of the physical parameterizations while benefiting the development and application of numerical models. Previously, several sensitivity studies were carried out to determine the effects of simulated regional climate on different parameterizations. For instance, using the Fourth-generation Pennsylvania State University (PSU)National Center for Atmospheric Research (NCAR) Mesoscale Model (MM4), Giorgi and Marinucci (1991) analyzed the sensitivity of the climate model over Europe to selected physical parameterizations (e.g., explicit moisture scheme) and lower boundary conditions (e.g., initial soil moisture and snow cover). When simulating the North American monsoon system using the Fifthgeneration PSU-NCAR Mesoscale Model (MM5), Gochis et al. (2002) found that substantial differences in precipitation, surface climate, and atmospheric stability occurred because of different convection parameterizations. More recently, Argüeso et al. (2011) evaluated the sensitivity of the Weather Research and Forecasting (WRF) Model to eight different combinations of cumulus, microphysics, and planetary boundary layer schemes (PBLSs) over a topographically complex region in southern Spain and found that both cumulus and PBLSs affect precipitation descriptions, while no noticeable differences were observed between the microphysics options. Similar to Argüeso et al. (2011), Crétat et al. (2012) quantified the uncertainties associated with some physical parameterizations for the core of a summer rainy season over southern Africa. All of these investigations have generally emphasized the importance of choosing physical schemes, 
especially cumulus schemes, in RCMs for use in different regions worldwide.

While several sensitivity studies have been performed using WRF, few, if any, have been performed to determine the GPH sensitivities to land surface schemes (LSSs) when using WRF models over continental China. As a key component of the climate system, the land surface transfers momentum, moisture, and heat to the overlaying atmosphere and modifies the climate states at the global and regional scales (e.g., Shukla and Mintz 1982; Xue 1997; Zeng et al. 2003; Chen and Xie 2012). Thus, the aim of this study is to quantify and explain the sensitivity of WRF-simulated GPH to different LSS models for continental China by using a case study.

Therefore, this paper is arranged as follows. In section 2, we describe the WRF Model, the experimental design, datasets, and relevant methods for analysis. Detailed quantitative data regarding the sensitivities of WRFsimulated GPH to different LSSs are presented in section 3, while a mechanistic explanation for the sensitivity is addressed in section 4 . In the final section, we summarize and provide a discussion of the study.

\section{Methodology}

\section{a. Model and experimental design}

Here, we applied the Advanced Research version of WRF (ARW), version 3 (Skamarock et al. 2008). The WRF Model is a next-generation mesoscale model that has been jointly developed by many scientific research and operational agencies and widely applied in various research and operational forecasting studies. WRF contains many advanced physical parameterization schemes. This paper uses nearly the same physical options for all simulations, that is, the Rapid Radiative Transfer Model (RRTM) longwave scheme (Mlawer et al. 1997), the MM5 shortwave scheme (Dudhia 1989), the modified version of the Kain-Fritsch scheme (Kain 2004), and the WRF singlemoment 5-class (WSM5) microphysics scheme (Hong et al. 2004; Hong and Lim 2006).

The following four LSSs are used in the model:

1) The five-layer thermal diffusion scheme (SLAB; Dudhia 1996) uses the force-restore method to solve the thermal diffusion equation for soil temperature in the five soil layers with thicknesses of $1,2,4,8$, and $16 \mathrm{~cm}$, whereas soil moisture values are determined using a season-dependent function of land use.

2) The Noah LSS (NOAH; Chen and Dudhia 2001; Ek et al. 2003) simulates soil variables (i.e., temperatures and moistures) for four layers with thicknesses of $10,30,60$, and $100 \mathrm{~cm}$ by using the force-restore method. The LSS accounts for detailed physical vegetation and soil hydrology processes and urbanization treatment.

3) The Rapid Update Cycle LSS (RUC; Smirnova et al. 1997, 2000) is characterized by a layer method for solving energy and moisture budget equations for soil variables and fluxes, which include soil, snow cover, and vegetation processes at six soil levels: 0,5 , 20, 40,160, and $300 \mathrm{~cm}$.

4) The Pleim-Xiu LSS (PLEX; Xiu and Pleim 2001) forecasts soil temperature, soil moisture, and canopy moisture for the two layers with thicknesses of 1 and $99 \mathrm{~cm}$, where three pathways for moisture fluxes are considered: evapotranspiration, bare soil evaporation, and wet-leaf evaporation.

Among the four LSSs, SLAB is the simplest in both structure and process physics, while NOAH, RUC, and PLEX are more sophisticated (e.g., the latter three LSSs include the sophisticated snow, soil, and vegetation physics). Moreover, the LSSs consider different soil layering schemes, which could affect the solutions.

The four LSSs in the WRF are used to investigate the sensitivity of the simulated height fields to the LSS choice for 12-member ensembles of simulations. In the next sections, the differences among the SLAB, NOAH, RUC, and PLEX simulations are compared. Because of the important role of soil moisture in land-atmosphere coupling (e.g., Koster et al. 2004) and according to Zeng et al. (2014), simulations are also performed using PLEX with initial soil moisture contents reduced by $25 \%$ (but with a 12 -member ensemble as the additional simulations for further discussion here), which are termed the PXsm simulations, with the abbreviations "PX" for the Pleim-Xiu LSS and "sm" for soil moisture.

Using different PBLSs, the other four-ensemble experiments are also carried out to compare the height sensitivity to the LSSs choice and that to the PBLSs. Four PBLSs in the WRF are employed here, that is, the Yonsei University scheme (YSUbl; where "bl" denotes boundary layer; Hong et al. 2006); the modified Mellor-Yamada scheme (MYJbl; Mellor and Yamada 1982; Janjić 2001); the quasi-normal scale elimination model (QNSEbl; Sukoriansky et al. 2006); and the PBLS of the asymmetric convective model, version 2 (ACM2bl; Pleim 2007).

All of the above-mentioned simulations employ the default land surface datasets of the WRF modeling system. However, these data may need updating for simulations. For example, the surface albedo and green vegetation fraction (GVF) were retrieved from the images of the Advanced Very High Resolution Radiometer (AVHRR) about 20 years ago (e.g., Gutman and Ignatov 1998). We updated the monthly surface albedo and GVF data and incorporate them into the WRF 
prepossessing system for the simulations with the Noah and Pleim-Xiu LSSs, which are termed the NHag and PXag simulations, respectively (e.g., the "a" and "g" denote albedo and GVF, respectively), to examine to what extent the simulated GPHs are affected by the updated data.

In summary, SLAB, NOAH, RUC, and PLEX (without the lowercase letters in naming) are investigated for comparisons among different LSSs, which is the focus of this study; PXsm and PXag (NHag) use the Pleim-Xiu (Noah) LSS and newly prescribed initial values for soil moisture, surface albedo, and GVF to compare with original PLEX (NOAH) results so as to investigate the effect of the related quantities; YSUbl, MYJbl, QNSEbl, and ACM2bl are used for simulations with different PBL schemes. Therefore, in total, $11 \times 12$ seasonal simulations are performed for the 11 ensembles in this study. In the following sections, the coupled-model simulations/ ensembles are referred to by the names of the schemes used, while for a specific LSS, a slightly complex expression is applied, such as "the SLAB LSS." Table 1 summarizes the physical options used in the 11 ensembles, and additional details regarding schemes are described by Skamarock et al. (2008) or in the above-mentioned references.

In this study, the simulation area (Fig. 1) is centered at $\left(37^{\circ} \mathrm{N}, 103^{\circ} \mathrm{E}\right)$, with $144 \times 116$ grid points at a horizontal resolution of $30 \mathrm{~km}$. A vertical resolution of 28 uneven levels was set with the top prescribed at $50 \mathrm{hPa}$. We choose three subareas in the investigations, that is, $D_{\mathrm{tb}}$, $D_{\mathrm{sc}}$, and $D_{\mathrm{ec}}$ included in Tibet, southern China, and eastern China with cold and high plateau, humid, and semihumid climates, respectively. We use the summer of 2003 as the simulation period, during which a prolonged, extremely heavy rainfall event and a persistent super heat wave occurred in eastern China (Zeng et al. 2012, 2014). All of these simulations were carried out for the approximate period from 1 May through 1 September 2003, and each simulation is a slightly perturbed, 12 -member ensemble with initial conditions chosen at 0000 , 0600, 1200, and 1800 UTC 1-3 May 2003 to make the simulation results more robust. The 4-month (MayAugust) integrations were performed using the firstmonth integration as a model spinup, and we used the June-August (JJA) results for analysis. Because the physical options of the simulations are nearly the same, except for the LSSs (or the PBLSs), the differences observed between the simulations result from the different LSSs (or the PBLSs).

\section{b. Datasets}

For the initial and boundary conditions of the simulations, the NCEP $1^{\circ} \times 1^{\circ}$ Final (FNL) analysis data are

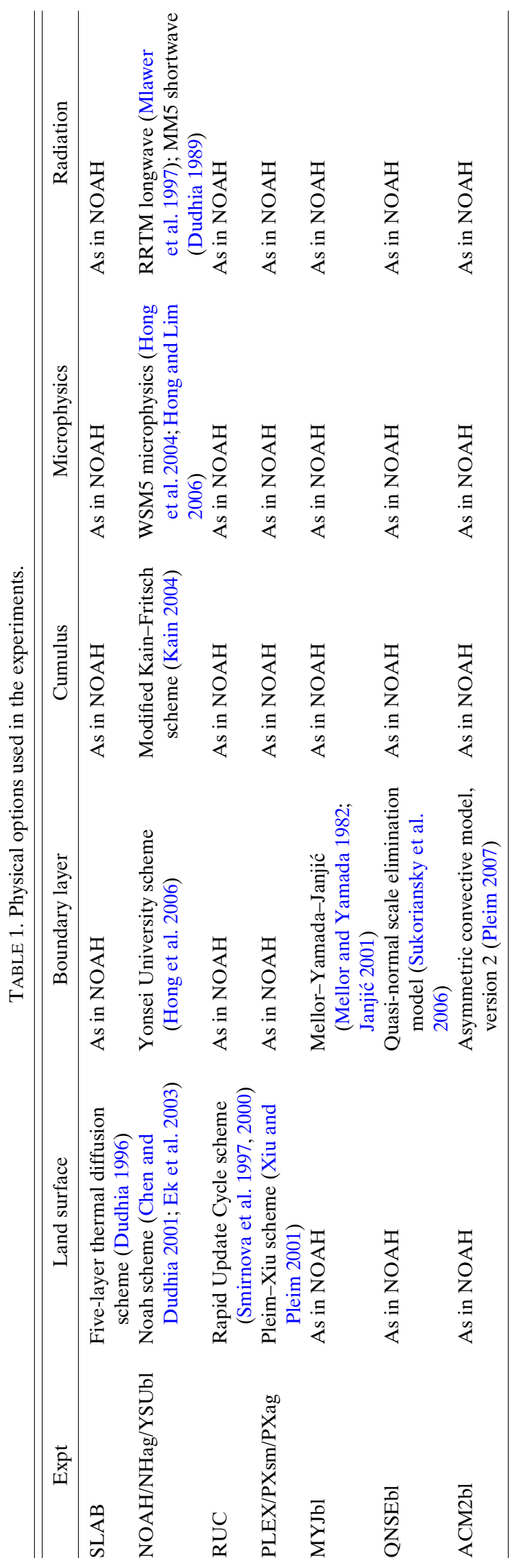




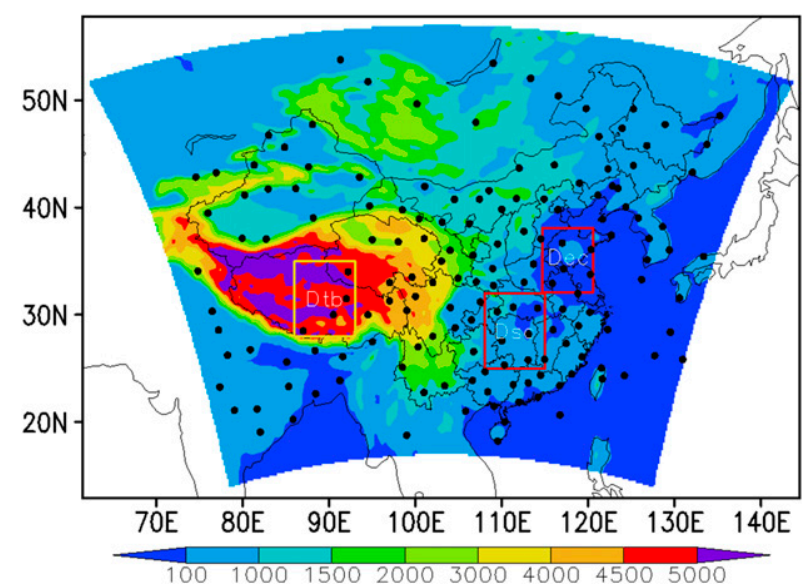

FIG. 1. Topographic elevations (m) and spatial distribution of selected observational stations within the model domain. The subareas denoted as $D_{\text {tb }}\left(28^{\circ}-35^{\circ} \mathrm{N}, 86^{\circ}-93^{\circ} \mathrm{E}\right), D_{\text {sc }}\left(25^{\circ}-32^{\circ} \mathrm{N}\right.$, $\left.108^{\circ}-115^{\circ} \mathrm{E}\right)$, and $D_{\text {ec }}\left(32^{\circ}-38^{\circ} \mathrm{N}, 115^{\circ}-120^{\circ} \mathrm{E}\right)$ are used in section 4 .

used. Because the horizontal resolution of $30 \mathrm{~km}$ in this study is much higher, the 38 -km NCEP Climate Forecast System Reanalysis (CFSR) data (http://cfs.ncep.noaa. gov/cfsr/) are also employed for the comparison.

Conventional radiosonde GPH data (available at 0000 and 1200 UTC each day during the summer of 2003) are used for validation. Considering the smoothly varying nature of GPH fields, which has been indicated by previous researchers (e.g., Reichler and Roads 2004), 161 meteorological stations with radiosonde data are assessed, which cover the domain area of continental China and the surrounding regions (Fig. 1).

For the PXag and NHag simulations, following Meng et al. (2014), we employ MODIS global 16-day $0.05^{\circ}$ bidirectional reflectance distribution function (BRDF)/ albedo data (i.e., black-sky albedo from MCD43C3 dataset), which were downloaded from the Land Processes Distributed Active Archive Center (LP DAAC) for the period from 1 May to 29 August 2003 to obtain monthly mean values. In addition, the GVF data were constructed following Jiang et al. (2010), with global MODIS vegetation indices (i.e., MOD13C 2 data from LP DAAC) provided monthly as a level-3 product projected on a $0.05^{\circ}$ geographic Climate Modeling Grid (CMG) (http://lpdaac.usgs.gov).

\section{c. Assessment measures}

To assess the performance of the model and investigate the sensitivity of the GPH simulations to different LSSs, we use monthly or seasonal-mean model bias (BIAS), root-mean-square error (RMSE), standard deviation (STD; $\mathrm{STD}_{M}$ and $\mathrm{STD}_{O}$ for simulations and observations, respectively), and correlation coefficient (CORR), which are computed as follows:

$$
\begin{aligned}
\text { BIAS } & =\bar{M}-\bar{O}, \\
\mathrm{RMSE} & =\sqrt{\frac{1}{N} \sum_{i=1}^{N}\left(M_{i}-O_{i}\right)^{2},} \\
\mathrm{STD}_{M} & =\sqrt{\frac{\sum_{i=1}^{N}\left(M_{i}-\bar{M}\right)^{2}}{N},} \\
\operatorname{STD}_{O} & =\sqrt{\frac{\sum_{i=1}^{N}\left(O_{i}-\bar{O}\right)^{2}}{N},}
\end{aligned}
$$

and

$$
\operatorname{CORR}=\frac{\sum_{i=1}^{N}\left(M_{i}-\bar{M}\right)\left(O_{i}-\bar{O}\right)}{\sqrt{\sum_{i=1}^{N}\left(M_{i}-\bar{M}\right)^{2}} \sqrt{\sum_{i=1}^{N}\left(O_{i}-\bar{O}\right)^{2}}}
$$

where $N$ is the total number of the stations, $M$ and $O$ represent the simulated and observed values of the quantity (i.e., GPH), respectively, the overbar denotes the mean values, and the subscript $i$ is for relevant stations.

\section{d. Atmospheric equation for GPH change}

Different land surface processes lead to different land surface fluxes, which cause changes in basic meteorological quantities, such as air pressure, temperature, and wind speed. Given an isolated column of air without horizontal divergence, higher heat fluxes can result in greater surface temperature and enhance the heights of the pressure levels under airmass conservation constraints. Theoretically, the specific mechanism of the LSS-induced effect on simulated GPHs can be explained as follows.

To simulate the domain at the seasonal or monthly scale, the following hydrostatic equation can be used:

$$
\frac{\partial p}{\partial H}=-\rho g^{*},
$$

where $p, H, \rho$, and $g^{*}$ stand for the air pressure, GPH, air density, and acceleration due to gravity (constant value), respectively. Using the equation of state for air

$$
p=\rho R T,
$$

where $R$ and $T$ are the gas constant and temperature, respectively. The following equation is obtained by integrating the above equation from the surface to $850 \mathrm{hPa}$ with the mean value theorem:

$$
\int_{p_{s}}^{p_{850}} \frac{d p}{p}=-\int_{H_{s}}^{H_{850}} \frac{g^{*}}{R T} d H,
$$


where $p_{850}=850 \mathrm{hPa}, H_{s}=$ constant, and $H_{850}$ and $p_{s}$ are temporal variables:

$$
\ln \frac{p_{850}}{p_{s}}=-\frac{g^{*}}{R \bar{T}}\left(H_{850}-H_{s}\right),
$$

where $\bar{T}$ is the mean temperature value of the air column between $H_{s}$ and $H_{850}$. Equation (9) indicates that $H_{850}$ is a function of the two atmospheric variables for a given location, that is, $p_{s}$ and $\bar{T}$. With respect to the function and variables, the differential form of (9) over a given area (e.g., eastern China) is obtained as follows:

$$
d\left[\ln \left(\ln \frac{p_{s}}{p_{850}}\right)\right]=d\left[\ln \left(\frac{g^{*}}{R \bar{T}} H_{850}\right)\right],
$$

or

$$
\frac{1}{\ln \frac{p_{s}}{p_{850}}}\left(\frac{d p_{s}}{p_{s}}\right)=\frac{d H_{850}}{H_{850}}-\frac{d \bar{T}}{\bar{T}} .
$$

Generally, $p_{s}$ varies little over the given area (e.g., for eastern China, $p_{s} \approx 1000 \mathrm{hPa}$ ). Thus,

$$
\frac{d H_{850}}{H_{850}} \approx \frac{d \bar{T}}{\bar{T}}+6.15 \frac{d p_{s}}{p_{s}} .
$$

The finite differential form of (12) can be rewritten as follows:

$$
\delta H_{850} \approx H_{850} \frac{\delta \bar{T}}{\bar{T}}+6.15 H_{850} \frac{\delta p_{s}}{p_{s}} .
$$

Similarly, for the 500-hPa GPH over the area,

$$
\delta H_{500} \approx H_{500} \frac{\delta \bar{T}}{\bar{T}}+1.44 H_{500} \frac{\delta p_{s}}{p_{s}} .
$$

In this study, the finite differential values in (13) and (14) can be regarded as the perturbations induced by the LSSs, and the contributions to the GPH changes from the changes in air temperature and surface pressure can be obtained.

\section{Simulation results}

Because of the complex, nonlinear, diurnal variations of GPH, we present the simulated GPHs for both 0000 and 1200 UTC, which is consistent with the radiosonde GPH data available. In addition, because LSSs mainly influence simulations from the lower to midtroposphere (see next section), we only provide results for the 850and 500-hPa levels.

\section{a. Summer means}

Because of the same lateral-boundary forcings, the LSS-simulated GPH fields are generally in agreement with analysis data (e.g., Giorgi and Mearns 1999). Figures 2 and 3 depict the simulated ensemble-mean seasonal (JJA)-mean 0000 UTC GPH fields and the CFSR fields at 500 and $850 \mathrm{hPa}$, respectively. For the 0000 UTC 500-hPa GPH, the PLEX analysis fields show generally consistent spatial results compared with the CFSR fields, for example, high GPH values in southern China and low values in the north with maximum values in the southeastern corner of the model domain, where the western Pacific subtropical high persists. However, the GPH values are generally approximately $20 \mathrm{gpm}$ higher than CFSR (Figs. 2a,b). In addition, the 850-hPa PLEX GPH pattern is similar to the analysis field [Figs. 3a,b; it is noteworthy that, because of high elevations and low air pressure at the surface of the Tibetan Plateau and part of inner Mongolia (Fig. 1), no GPH output is given for $850 \mathrm{hPa}$ over the area], except for the values in the eastern part of the domain, which are generally lower than those from reanalysis data. Meanwhile, apparently systematic differences between different schemes can be observed. As shown in Fig. $2 \mathrm{c}$ for $500 \mathrm{hPa}$, the PLEX GPH is consistently higher than the SLAB GPH over most continental areas of China to the west of $\sim 110^{\circ} \mathrm{E}$, with a large total area of differences of more than $6 \mathrm{gpm}$ in western China. In southeastern China, the Korean Peninsula, and over the East China Sea, SLAB provides obviously higher values than PLEX. These values of LSS-induced differences are very large compared with those of Shabbar et al. (1990), who provided a 500-hPa summer GPH anomaly (with a value of $\sim 7 \mathrm{gpm}$ for the largest anomaly amplitude over a relatively small area in continental China) when analyzing the Northern Hemisphere GPHs from 1946 to 1985. It can be concluded that because different LSSs produce different surface fluxes that further affect simulated atmospheric states, GPH fields (even over ocean) can be substantially modified as PLEX is used instead of SLAB. The NOAH GPH is relatively similar to PLEX (Fig. 2d). Compared with PLEX, RUC results in obviously higher simulated values over most of the north (north of $30^{\circ} \mathrm{N}$ ), with a large total area of GPH differences of more than $10 \mathrm{gpm}$ around northern China, and provides slightly lower values south of $30^{\circ} \mathrm{N}$ (Fig. 2e). At $850 \mathrm{hPa}, \mathrm{SLAB}$ simulates significantly higher values than PLEX, with differences of more than $10 \mathrm{gpm}$ over most areas of eastern China (Fig. 3c). In addition, as shown in Fig. 3d (Fig. 3e), the NOAH (RUC) 850-hPa GPHs are slightly higher (lower) than the PLEX results. Furthermore, in the comparisons among SLAB, NOAH, 
(a) CFSR seasonal Mean

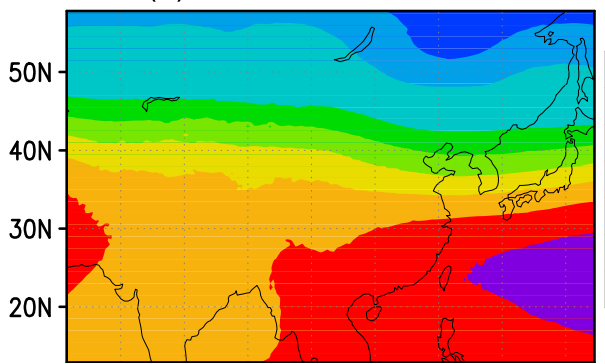

(c) Mean SLAB-PLEX Difference

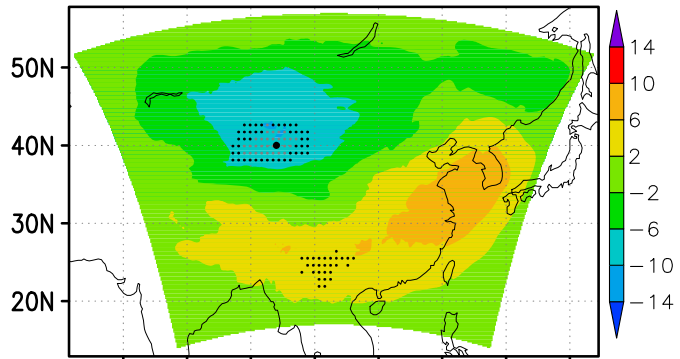

(e) Mean RUC-PLEX Difference

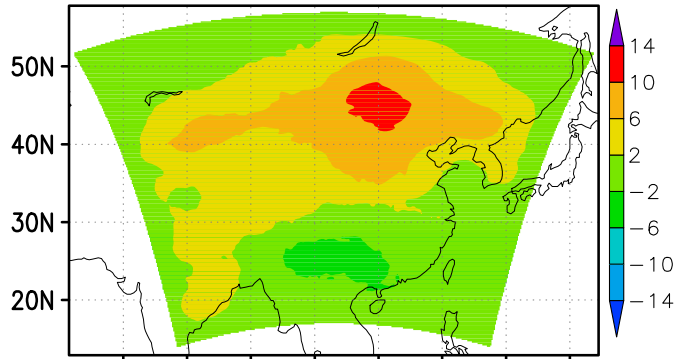

(g) Mean RUC-SLAB Difference

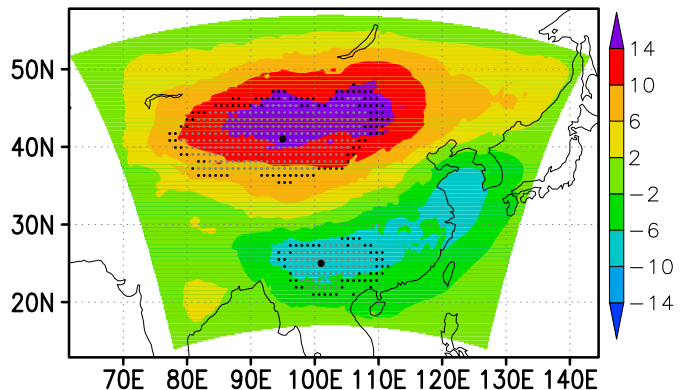

(b) PLEX seasonal Mean

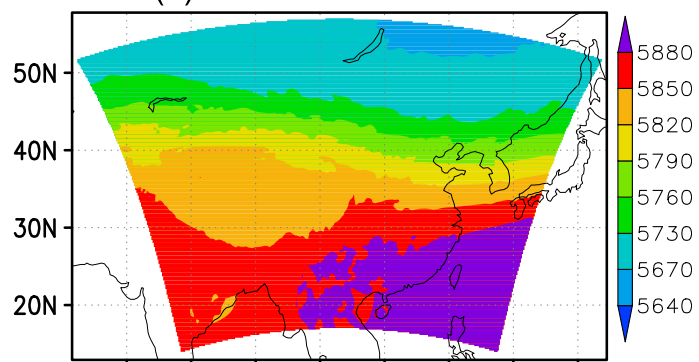

(d) Mean NOAH-PLEX Difference

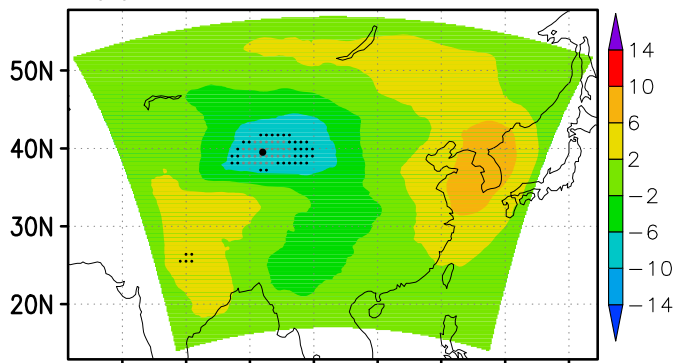

(f) Mean NOAH-SLAB Difference

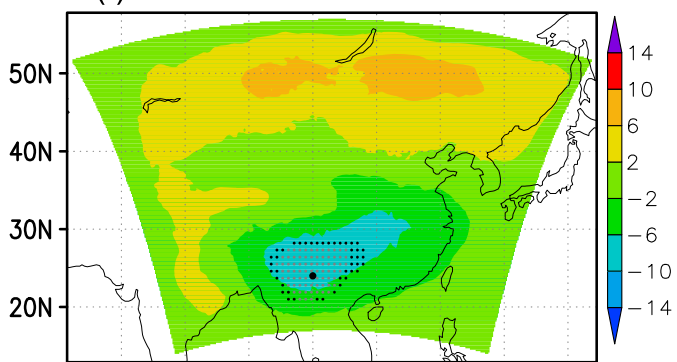

(h) Mean NOAH-RUC Difference

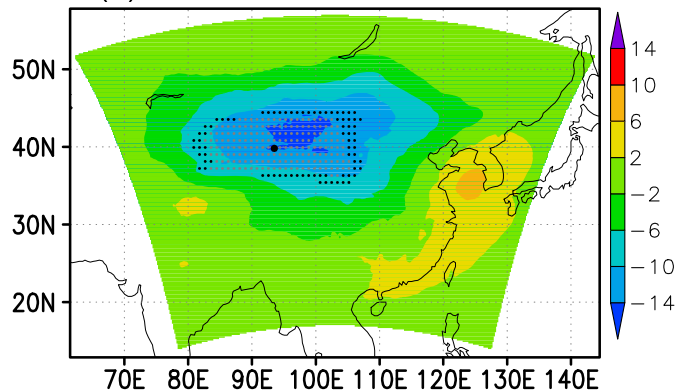

FIG. 2. Ensemble- and seasonal-mean GPH distributions at $500 \mathrm{hPa}$ for $0000 \mathrm{UTC}$ (gpm), where regions with significant LSS-induced differences are marked with gray and black dots. Specifically, gray (black) dots indicate the ensemble-mean GPH differences that are significant at the 5\% (10\%) level, according to the Student's $t$ test for the time series of daily GPH values of the study period.

and RUC, large 500-hPa differences between SLAB and NOAH (RUC and SLAB/NOAH) are found over southwestern (northwestern) China (Figs. 2f-h), with even larger differences at $850 \mathrm{hPa}$ (Figs. $3 \mathrm{f}-\mathrm{h}$ ).

Because of the higher level of $500 \mathrm{hPa}$ in comparison with $850 \mathrm{hPa}$, the GPH difference fields at $500 \mathrm{hPa}$ are more systematically distributed. In addition, the fields are generally characterized by two large areas with opposite signs (e.g., Figs. 2c-h). This finding suggests that LSSinduced GPH difference fields generally show spatially large-scale features, which are produced by the simulations with a relatively high resolution (i.e., $30 \mathrm{~km}$ ) in this study.

Additionally, Figs. 2 and 3 also present the Student's $t$-test results of different LSS-simulated ensemble-mean 
(a) CFSR Seasonal Mean

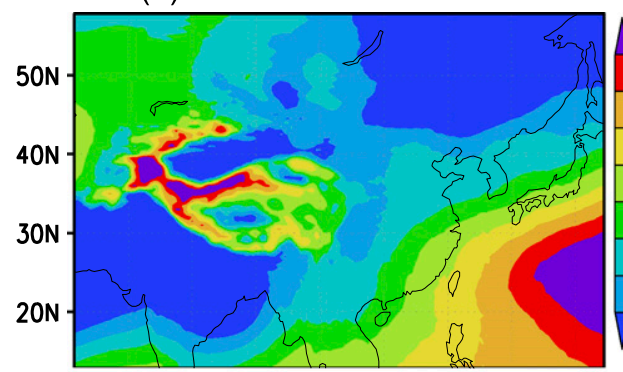

(c) Mean SLAB-PLEX Difference

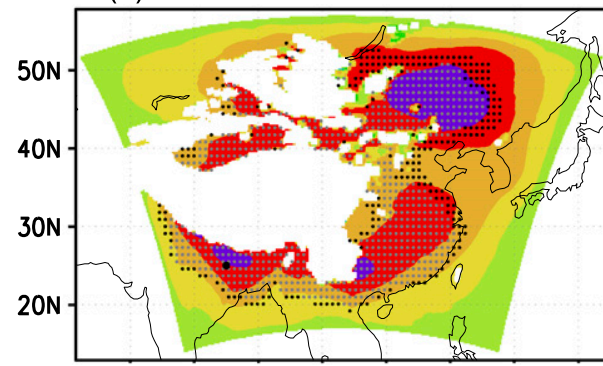

(e) Mean RUC-PLEX Difference

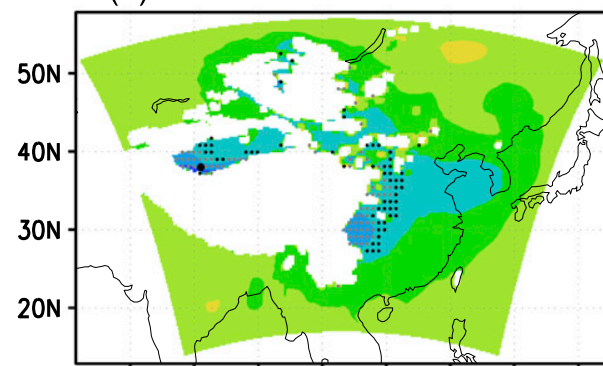

(g) Mean RUC-SLAB Difference

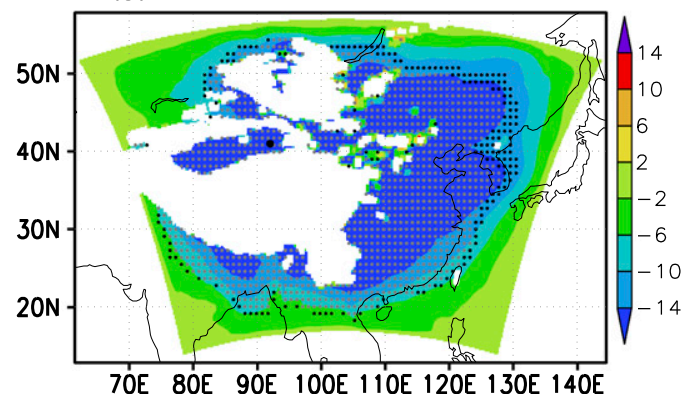

(b) PLEX Seasonal Mean

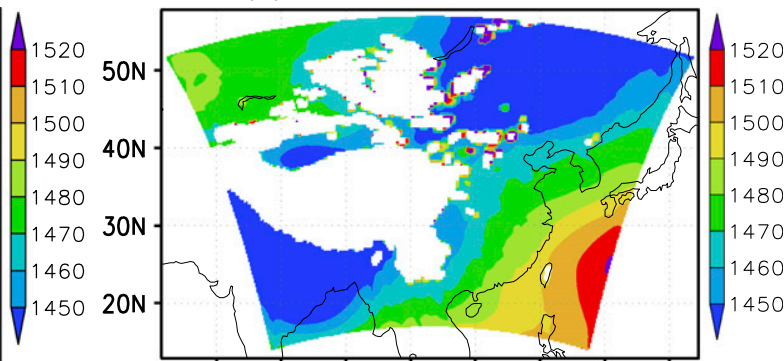

(d) Mean NOAH-PLEX Difference
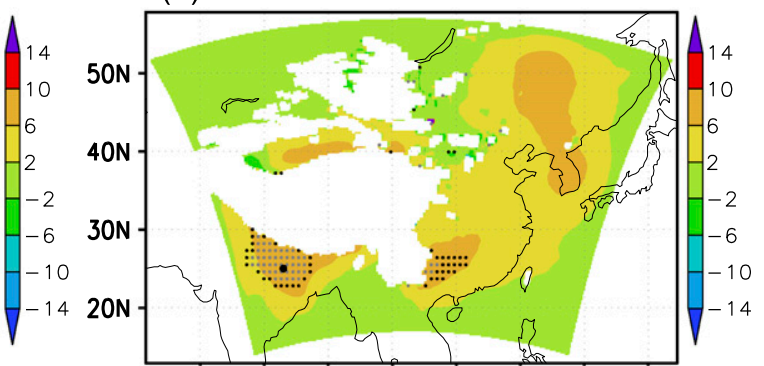

(f) Mean NOAH-SLAB Difference

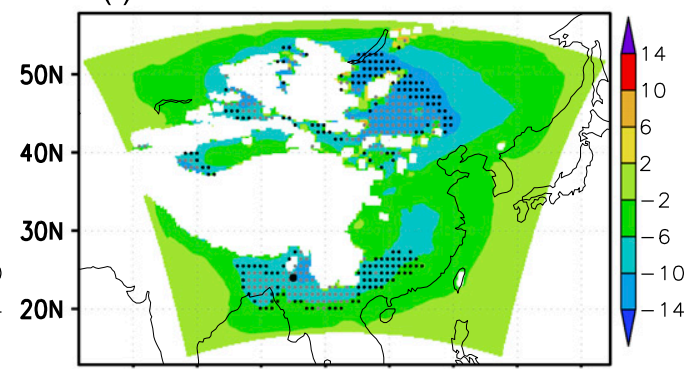

(h) Mean NOAH-RUC Difference

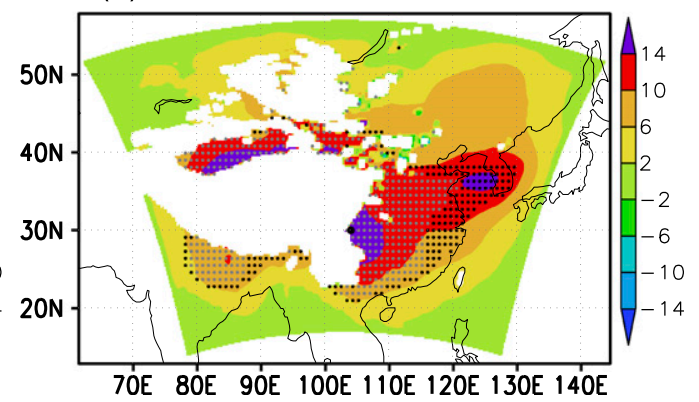

FIG. 3. As in Fig. 2, but for $850 \mathrm{hPa}$.

GPH fields and show that GPH differences can be significant at the $5 \%$ and $10 \%$ levels for very large areas over continental China, especially at $850 \mathrm{hPa}$, which corresponds with the above results. For instance, although at $500 \mathrm{hPa}$ the total area with the significantly large SLABPLEX differences is relatively small (Fig. 2c), it is much larger at $850 \mathrm{hPa}$ (Fig. 3c), which agrees well with the distributions of the GPH difference fields. In addition, the largest differences occur between SLAB and RUC over northwestern China at $500 \mathrm{hPa}$ and over most of the simulation domain at $850 \mathrm{hPa}$ according to the Student's $t$ tests (Figs. $2 \mathrm{~g}, 3 \mathrm{~g}$ ). Considering the high elevations and low air pressure at the surface of the Tibetan Plateau and in part of inner Mongolia (Fig. 1), the largest differences occupy most of the areas, with surface pressures of more than $850 \mathrm{hPa}$.

Figure 4 is similar to Figs. 2 and 3 but for the differences in ensemble maximum and minimum, where the ensemble maximum (minimum) is the simulation with the highest (lowest) GPH seasonal-mean value from one 
(a) Maximum RUC-NOAH $500 \mathrm{hPa}$

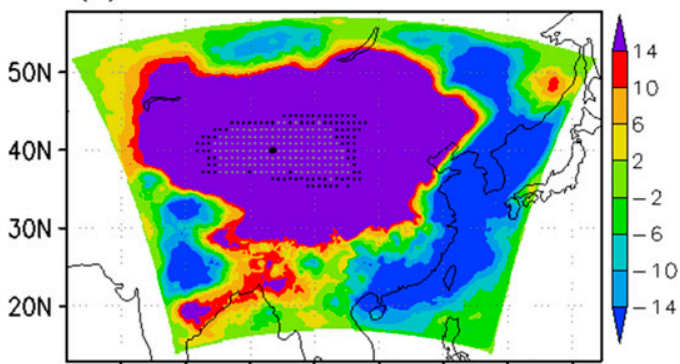

(c) Maximum RUC-SLAB $500 \mathrm{hPa}$

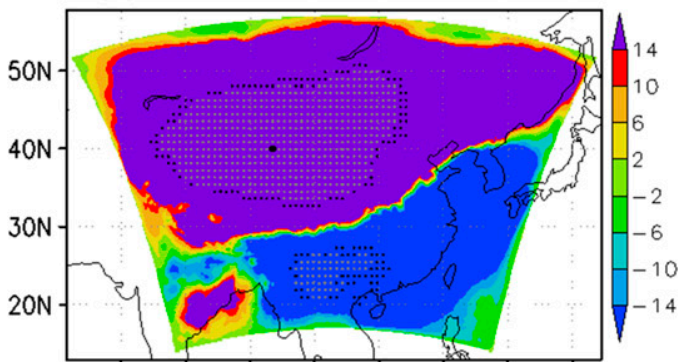

(e) Minimum RUC-NOAH $500 \mathrm{hPa}$

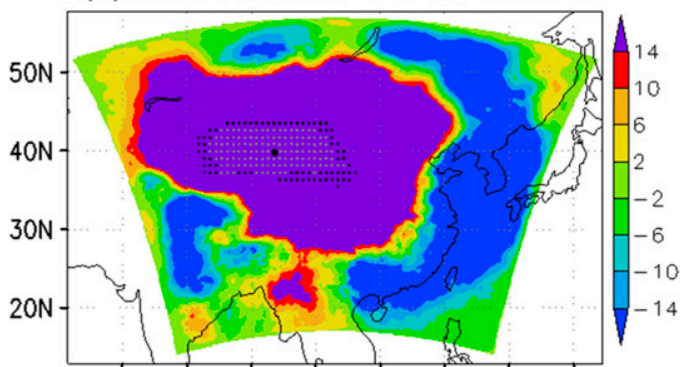

(g) Minimum RUC-SLAB $500 \mathrm{hPa}$

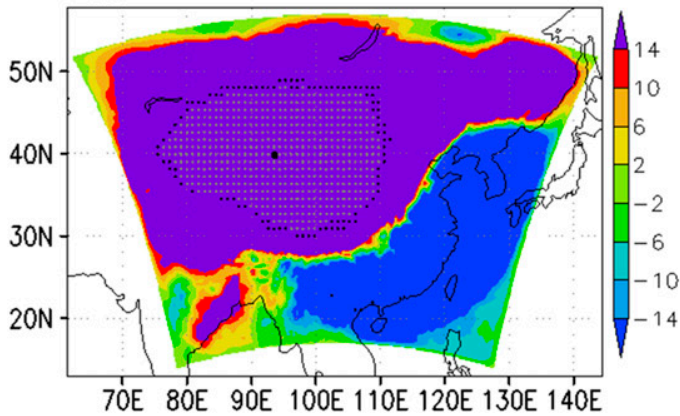

(b) Maximum RUC-NOAH $850 \mathrm{hPa}$

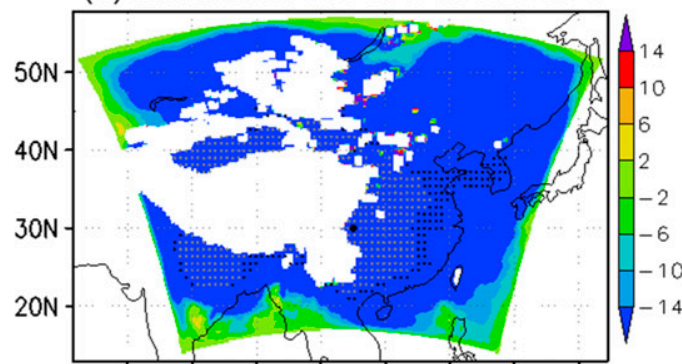

(d) Maximum RUC-SLAB $850 \mathrm{hPa}$

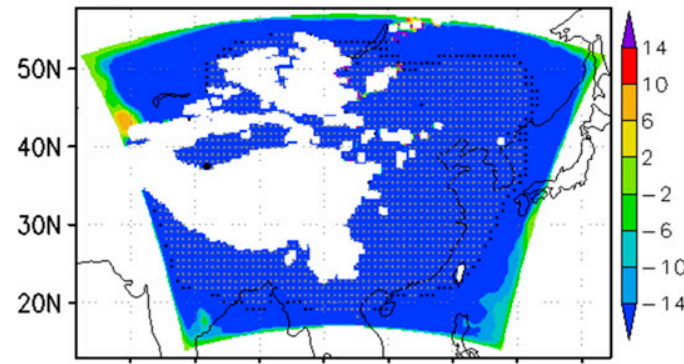

(f) Minimum RUC-NOAH $850 \mathrm{hPa}$

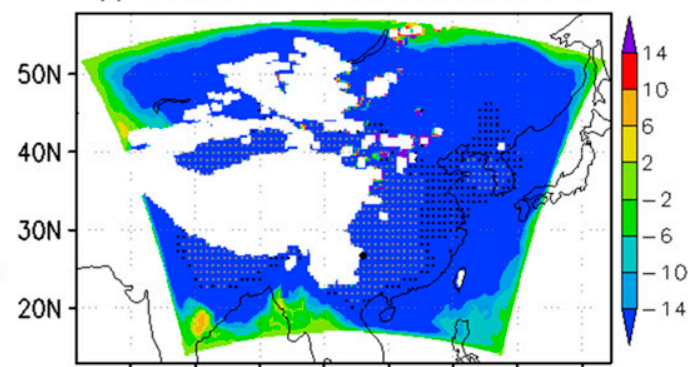

(h) Minimum RUC-SLAB $850 \mathrm{hPa}$

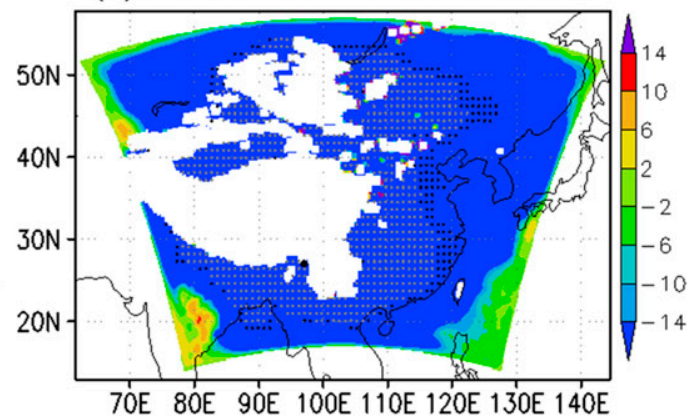

FIG. 4. As in Fig. 2, but for differences in ensemble max and min at 500 and $850 \mathrm{hPa}$, where the ensemble max ( $\min )$ has the highest (lowest) GPH seasonal-mean value from one of the 12 members in an ensemble.

of the 12 members in an ensemble. Rather than the differences in ensemble mean (Figs. 2 and 3), the differences in ensemble maximum and minimum are statistically significant over much larger areas. This result indicates that the simulations of extreme values are very sensitive to the LSS choice.

As shown in Fig. 5a for BIAS, the effects of the LSSs on the GPH results depend on the characteristic pressure levels. As indicated by Zhuang et al. (2006), 0000 UTC GPH fields show forecast errors that are similar to those of 1200 UTC GPH fields from 14 May to 14 July 2003. This study confirms that the 0000 UTC BIASs are similar to those at 1200 UTC when using different models. At $500 \mathrm{hPa}$, the four LSS ensembles provide higher ensemble-mean seasonal GPHs than the observed values (e.g., the RUC ensemble-mean 
(a) BIAS Induced by the LSSs

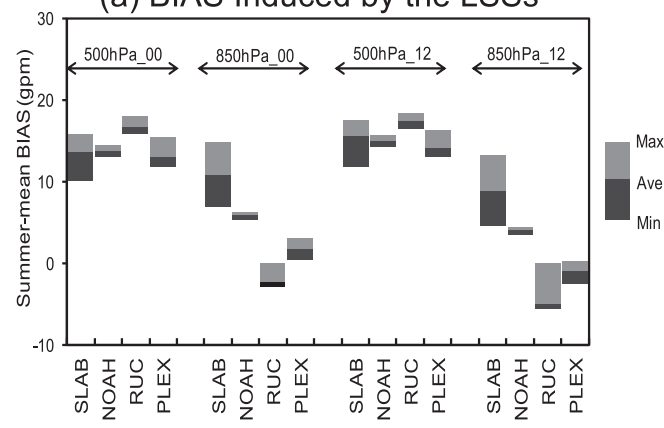

(c) GPH BIAS Profile at Zheng Zhou

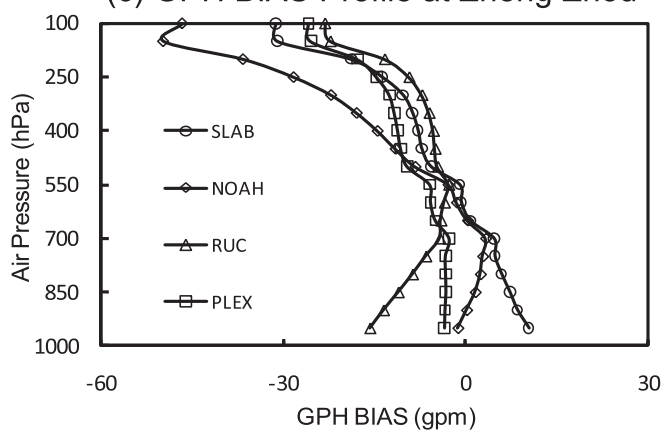

(b) RMSE Induced by the LSSs

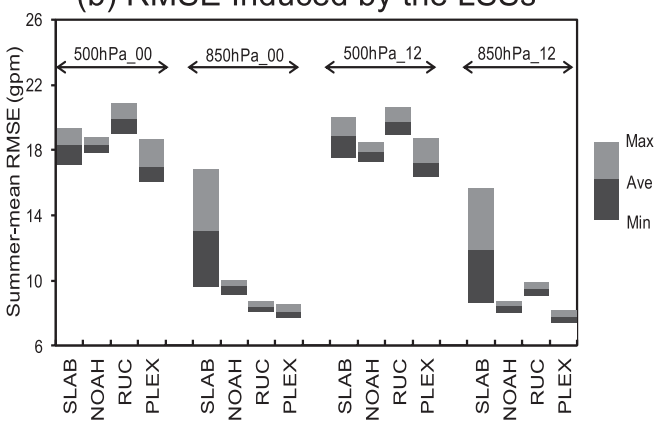

(d) Std Dev Difference by the LSSs

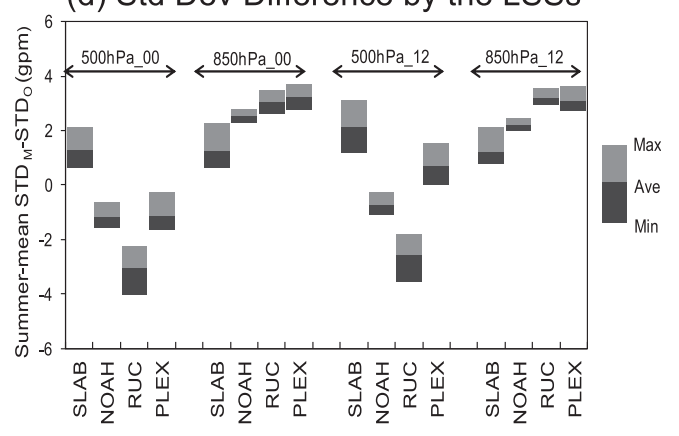

FIG. 5. Ensemble results of (a) BIAS, (b) RMSE, (c) GPH BIAS profiles at Zhengzhou station $\left(34.72^{\circ} \mathrm{N}, 113.65^{\circ} \mathrm{E}\right)$, and (d) the difference of the std dev of the summer-mean GPHs over China at 500 and $850 \mathrm{hPa}$ for 0000 and 1200 UTC, where the "Ave," "Max," and "Min" levels in the shaded bars denote the 12-member ensemble mean, max, and min, respectively.

seasonal GPHs for 0000 and 1200 UTC are higher than those observed for 17.4 and $17.5 \mathrm{gpm}$, respectively). The 500-hPa BIAS differences among the LSS ensembles are generally lower than $5 \mathrm{gpm}$, and the PLEX GPHs are generally the most similar to the observations. However, for ensemble means at $850 \mathrm{hPa}$, obvious BIAS differences are produced among the LSS ensembles, in which the PLEX BIAS values are the lowest in amplitude, followed by NOAH, RUC, and SLAB (e.g., when comparing the seasonal-mean 1200 UTC GPHs with the observations, SLAB and NOAH are 8.4 and $4.1 \mathrm{gpm}$ higher, respectively, while RUC and PLEX are 5.0 and $1.2 \mathrm{gpm}$ lower), and large differences were observed among the LSS ensembles. Particularly, the RUC-SLAB difference is approximately $13 \mathrm{gpm}$ and approximately $260 \%$ of the RUC BIAS. These LSS-induced BIAS differences also represent the LSS-induced GPH differences. In addition, these values are area averaged over the entire model domain, and larger and much larger values exist over part of continental China, as shown in the above LSS-induced difference fields (Figs. 2c,e,g). Relative to SLAB, the other ensembles can significantly improve the 850-hPa GPH simulation, and the low-level GPH simulation is sensitive to the LSS choice. Moreover, the 500- and 850-hPa GPH BIAS values from SLAB are both very large, while the BIAS values from the other ensembles are reduced as the pressure decreases (Fig. 5a). Among the LSS ensembles, RUC produces the lowest height and results in a difference of more than 20 gpm (e.g., the 1200 UTC RUC BIAS difference between 500 and $850 \mathrm{hPa}$ ).

Regarding the ensemble- and seasonal-mean RMSE (Fig. 5b) at $500 \mathrm{hPa}$, both 0000 and 1200 UTC values are near $18 \mathrm{gpm}$, which shows no large LSS-induced differences. At $850 \mathrm{hPa}$, some large differences are produced, with the maximum RMSE occurring for SLAB and lower, similar values occurring for the other LSS ensembles (e.g., compared to SLAB, the PLEX RMSE is reduced by over $50 \%$ ). Overall, these RMSEs agree well with those of BIAS. The area-averaged BIAS and RMSE values both generally increase as the pressure level increases over most of the simulation area (Figs. 5a,b) because the height fields are, in the context of hydrostatics, computed from temperature, moisture, surface height, and surface pressure, and lower-level errors are accumulated and added to the upper-level errors. However, for more localized regions, the GPH profiles are quite complex (e.g., Fig. 5c for Zhengzhou station), as is explained in section 4 . In addition, the variations (with pressure level) and amplitudes of the 
RMSE and BIAS values are consistent with the GCM results of Xu et al. (2001), who used standard deviations to forecast errors in height and suggested that LSS-induced errors could substantially influence GPH forecasts.

Simulation standard deviations (i.e., $\mathrm{STD}_{M}$ ) closer to the observation standard deviation (i.e., $\mathrm{STD}_{O}$ ) correspond with better LSS simulations of the spatial GPH variability. Compared with the ensemble-mean $\mathrm{STD}_{M}$ and $\mathrm{STD}_{O}$ values of $\sim 60 \mathrm{gpm}$, both the $500-\mathrm{hPa} \mathrm{STD}_{M}-$ $\mathrm{STD}_{O}$ values are small, with the PLEX $\mathrm{STD}_{M}$ values closer to the observed values (Fig. 5d). At $850 \mathrm{hPa}$, the schemes have little $\mathrm{STD}_{M}$ difference (generally lower than $3 \mathrm{gpm}$ ), and all of the LSS ensembles slightly overestimate the spatial variability, with SLAB providing the best performance. All of the LSS ensembles appear to simulate the GPH spatial variability well, and the variability is only slightly sensitive to the LSS choice.

The 12-member ensemble spread (i.e., the standard deviation with respect to the ensemble mean; not shown) is very low for the above 12-member BIAS, RMSE, and $\mathrm{STD}_{M}-\mathrm{STD}_{O}$ results. For instance, SLAB gives the largest spread $(1.65 \mathrm{gpm})$ for $500-\mathrm{hPa}$ 0000 UTC BIAS, which is much lower than the ensemble mean $(\sim 15 \mathrm{gpm})$ and is consistent with the range of BIAS change (Fig. 5a). All of these results confirm the robustness of the conclusions addressed above.

Generally, the LSS ensembles can produce general seasonal-mean GPH patterns. While the performances of the ensembles when simulating the $500-\mathrm{hPa}$ GPH field are not noticeably different over the entire domain, the LSS-induced differences are likely substantial at subregional scales (e.g., northwestern China). In addition, at $850 \mathrm{hPa}$, the overall performances can be substantially different, which indicates that the simulated GPH field is even more sensitive to the LSS choice in the lower troposphere than in the midtroposphere. For GPH fields at $500 \mathrm{hPa}$, all of the LSS simulations produce large ensemble-mean BIAS values, while the values from the LSS ensembles, except for SLAB, are reduced at $850 \mathrm{hPa}$. Overall, PLEX performs the best, followed by NOAH and RUC and SLAB. In addition, SLAB presents the largest ranges (or ensemble spread values) of BIAS, RMSE, and $\mathrm{STD}_{M}-\mathrm{STD}_{O}$, which suggests the largest uncertainty induced by the scheme. The worst performance of SLAB may largely occur because among the four LSSs, the five-layer thermal diffusion scheme (i.e., SLAB) is the simplest in complexity. Thus, the SLAB LSS poorly reflects the actual land surface characteristics and therefore decreases the computational precision of the surface fluxes. For instance, unlike the other LSSs in the WRF, SLAB does not calculate soil moisture. Instead, SLAB considers soil moisture as a seasonally varying function of land-cover type and does not explicitly consider the effects of vegetation (Dudhia 1996).

The above-mentioned GPH differences are directly caused by changes in the surface fluxes of the LSSs. As an example of how well the LSSs reproduce surface fluxes, Fig. 6 displays LSS-simulated evapotranspiration fields and an observation-based field (Miralles et al. 2013). These results show that while LSSs can reasonably simulate fields with high correlations (Table 2), some large differences are also clearly presented [e.g., SLAB (PLEX) gives apparently higher values for northwestern (eastern) China].

The results show that simulated higher evaporation leads to lower GPH fields in a given area. For instance, compared with SLAB, PLEX simulates higher evaporation (Fig. 6a vs Fig. 6d) and lower sensible heat flux (not shown) throughout most of southeastern continental China, which directly results in lower PLEX surface temperatures in the area. This lower temperature (colder air) reduces the pressure levels under the hydrodynamic balance, for example, PLEX provides lower GPHs than SLAB over most of the southeast (Fig. 3c). Overall, higher simulated evaporation generally reduces pressure levels and vice versa (further discussion is given in section 4).

Compared with the observations, PLEX presents much higher evaporation (Fig. 6d vs Fig. 6f) over the southeast. However, the overall PLEX 850-hPa GPH field is nearly unbiased (Fig. 5a). This result indicates the complexity of the behaviors by the LSSs in the context of the GPH simulation, as is in agreement with previous studies; for example, Jerez et al. (2013) showed that no single ensemble member can present results better than the others in every situation by a multiphysics ensemble of regional climate simulations. This finding suggests that even if an LSS ensemble presents a "perfect" GPH field, the simulated surface fluxes might be biased with large amplitudes. In addition, unbiased simulated surface fluxes do not necessarily result in well-simulated GPH fields when using a coupled model.

Additional PXsm simulations with reduced soil moisture contents show that the simulated evaporation is still higher than the observations (Fig. 6f) even when the initial soil moisture content is decreased by $25 \%$. Because the initial soil moisture content is generally not negatively biased by $25 \%$ over all of continental China [e.g., compared with results by Zhang et al. (2008)], biased PLEX evaporation likely results from parameterizations other than the initial values. Based on the above result with a consideration of previous investigations that have highlighted the importance of initial land states (e.g., Guo et al. 2011), it is suggested that improving land initialization is inadequate for achieving better model performance for 
(a) SLAB

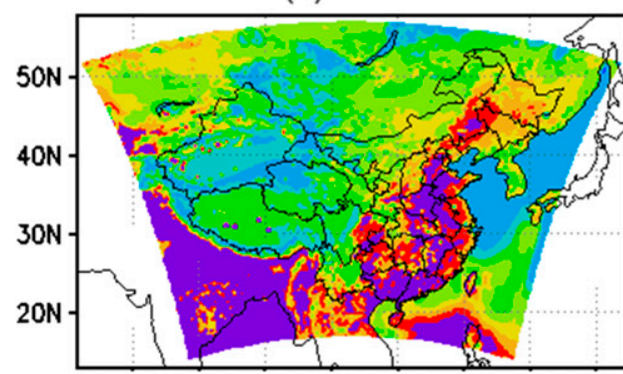

(c) RUC

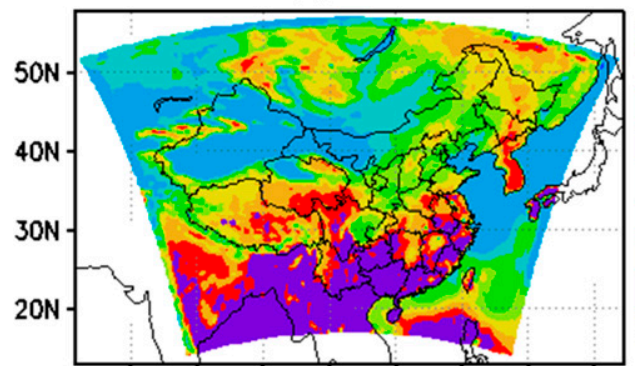

(e) PXsm

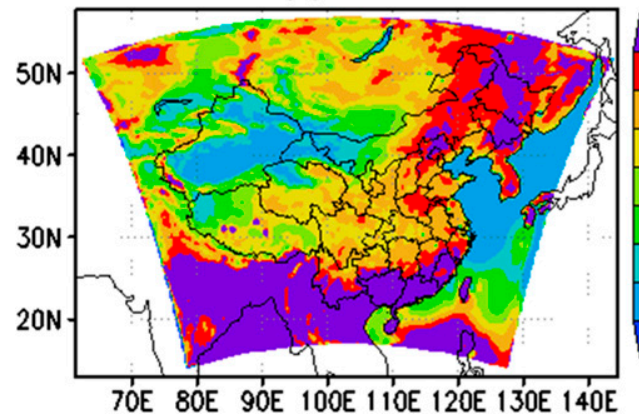

(b) NOAH

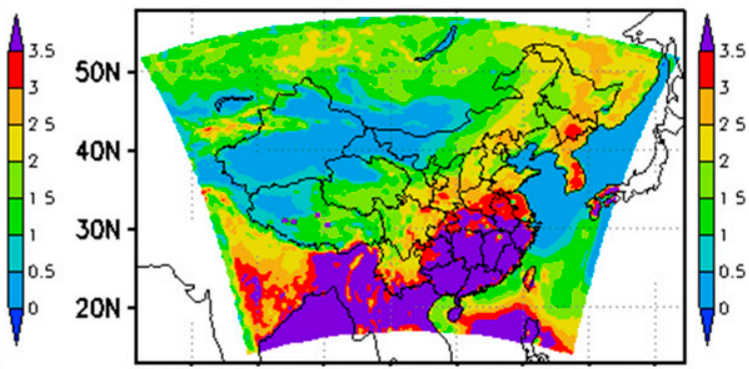

(d) PLEX

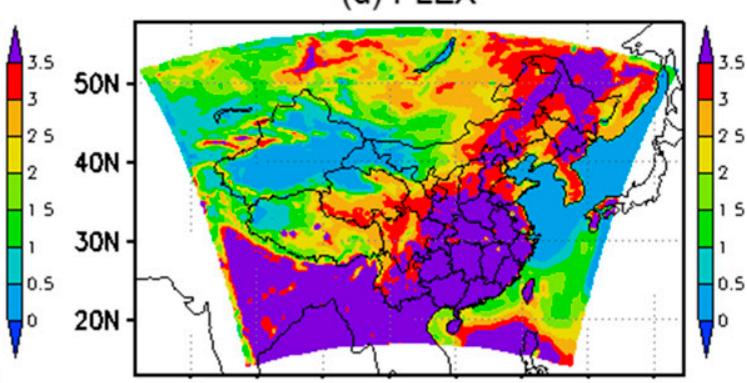

(f) OBS (Miralles et al.)

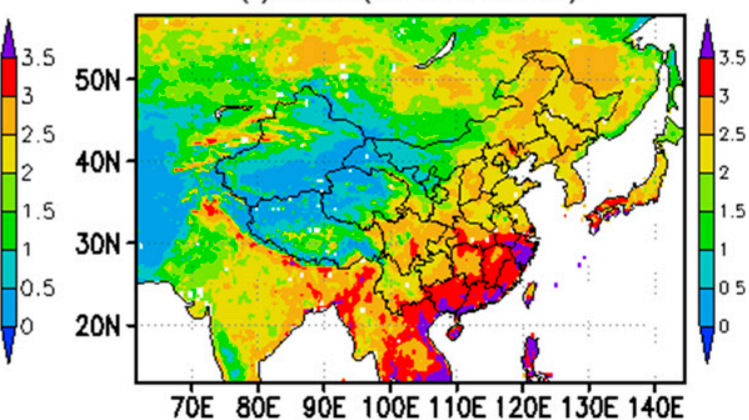

FIG. 6. (a)-(e) LSS-simulated ensemble-mean summer evapotranspiration fields $\left(\mathrm{mm} \mathrm{day}^{-1}\right)$ and (f) the observation-based evapotranspiration field $\left(\mathrm{mm} \mathrm{day}^{-1}\right)$, which has a resolution of $0.25^{\circ}$ over land and was obtained from Miralles et al. (2013).

continental China in seasonal simulations/forecasts using coupled models. However, the parameterizations should be improved simultaneously.

Furthermore, both the NHag and PXag results (see supplemental material) are shown to be only slightly different from the NOAH and PLEX results, respectively, which demonstrates that the BIASs are caused by different land parameterizations rather than the use of the satellite data (i.e., surface albedo and GVF).

TABLE 2. Ensemble-mean seasonal CORR, BIAS, RMSE, $\mathrm{STD}_{M}$, and $\mathrm{STD}_{M}-\mathrm{STD}_{O}$ for the LSS-simulated evapotranspiration over land, where observations are from Miralles et al. (2013) and $\mathrm{STD}_{O}=0.87 \mathrm{~mm} \mathrm{day}^{-1}$.

\begin{tabular}{lccccc}
\hline \hline & CORR & BIAS $\left(\mathrm{mm} \mathrm{day}{ }^{-1}\right)$ & $\left.\mathrm{RMSE}_{(\mathrm{mm} \mathrm{day}}{ }^{-1}\right)$ & $\mathrm{STD}_{M}\left(\mathrm{~mm} \mathrm{day}^{-1}\right)$ & $\begin{array}{c}\mathrm{STD}_{M}-\mathrm{STD}_{O} \\
\left(\mathrm{~mm} \mathrm{day}^{-1}\right)\end{array}$ \\
\hline SLAB & 0.51 & 0.17 & 1.19 & 1.35 & 0.48 \\
NOAH & 0.73 & -0.03 & 0.85 & 1.24 & 0.37 \\
RUC & 0.55 & -0.43 & 0.97 & 0.94 & 0.07 \\
PLEX & 0.70 & 0.68 & 1.24 & 1.45 & 0.58 \\
PXsm & 0.61 & 0.56 & 1.13 & 1.31 & 0.44 \\
PXag & 0.71 & 0.71 & 1.25 & 1.26 & 0.59 \\
NHag & 0.74 & 0.08 & 0.84 & & 0.39 \\
\hline
\end{tabular}


(a) NOAH-SLAB $500 \mathrm{hPa}$

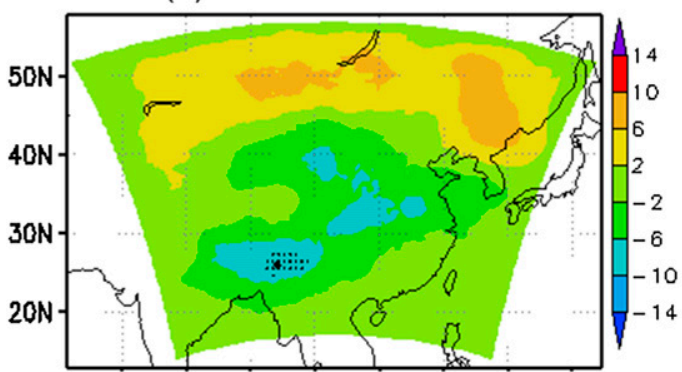

(c) RUC-SLAB $500 \mathrm{hPa}$

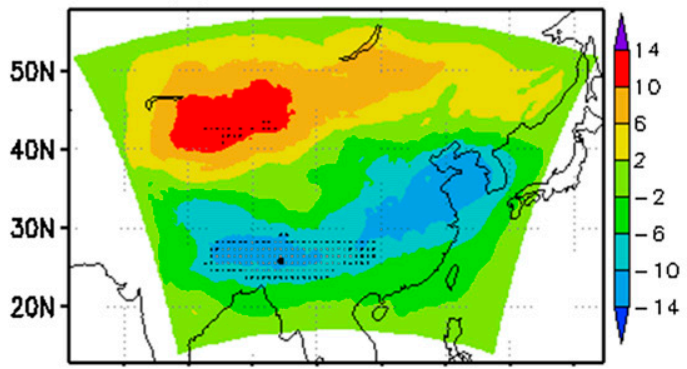

(e) PLEX-SLAB $500 \mathrm{hPa}$

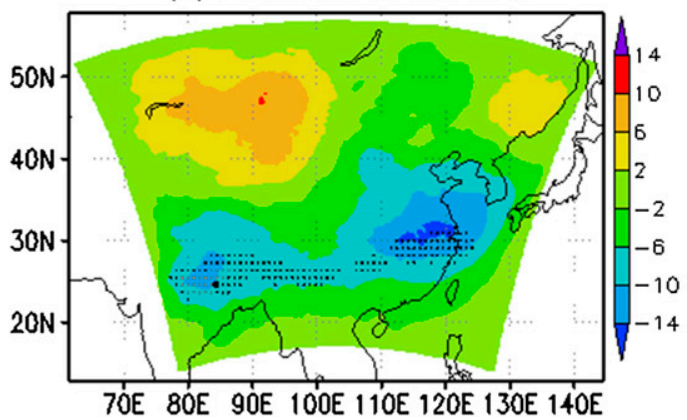

(b) NOAH-SLAB $850 \mathrm{hPa}$

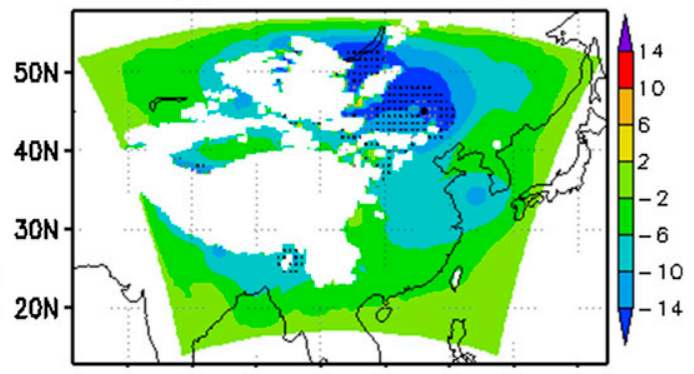

(d) RUC-SLAB $850 \mathrm{hPa}$

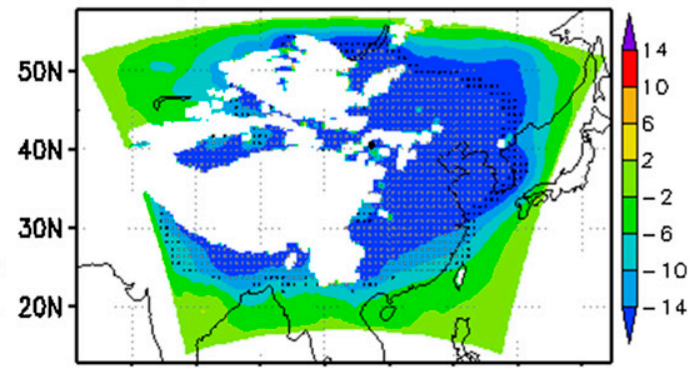

(f) PLEX-SLAB $850 \mathrm{hPa}$

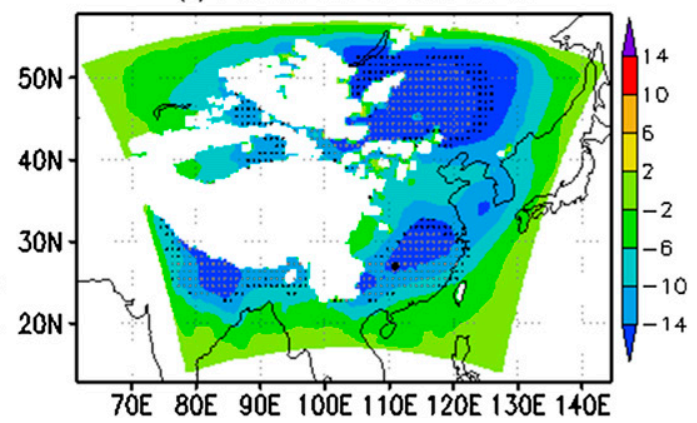

FIG. 7. Ensemble-mean monthly GPH differences between SLAB and the other LSSs for 0000 UTC in July (gpm).

\section{b. Monthly means}

In addition to the consistency of the ensemble-mean monthly GPH fields with the corresponding NCEP reanalysis (not shown), large differences are induced by the LSS choice, which is more apparent in the lower layer. Figure 7 provides the mean GPH difference fields for 0000 UTC in July among the SLAB and other LSSs. For $850 \mathrm{hPa}$, the monthly GPH field is generally more sensitive to the LSSs than at the seasonal scale (e.g., Figs. 3f,g vs Figs. 7b,d, respectively), which is the most obvious for eastern China; for example, RUC-SLAB differences of more than $20 \mathrm{gpm}$ cover a large total area in the region (not shown).

As shown in Fig. 8 a for 0000 UTC, the ensemble-mean monthly GPH values from the four LSSs are higher than observations at $500 \mathrm{hPa}$, which is consistent with the above-mentioned results for the seasonal scale. However, very large BIAS differences are observed between the monthly and seasonal results that are higher than the differences in the seasonal-mean BIAS (Fig. 5a).

In addition, at the monthly scale, the low-level GPH simulation is more sensitive to LSS choice than at the upper level (e.g., all of the 500-hPa ensemble means of monthly BIAS are positive with relatively small differences, while the $850-\mathrm{hPa}$ ensemble means of monthly BIAS can change from positive to negative values with large amplitudes). Generally, lower 850-hPa BIAS and RMSE values can be clearly identified (Figs. 8a,b); the mean values of RMSE and those of $\mathrm{STD}_{M}-\mathrm{STD}_{O}$ increase with time at the monthly scale (Figs. 8b,c).

Because of differences among the LSSs, the monthly variations of the ensemble-mean BIAS also differ complexly. For instance, among the values by different LSSs for 0000 UTC at $500 \mathrm{hPa}$ (Fig. 8a), the SLAB BIAS values are $12.8,19.4$, and $8.2 \mathrm{gpm}$, which basically correspond to the minimum, maximum, and minimum for June, 

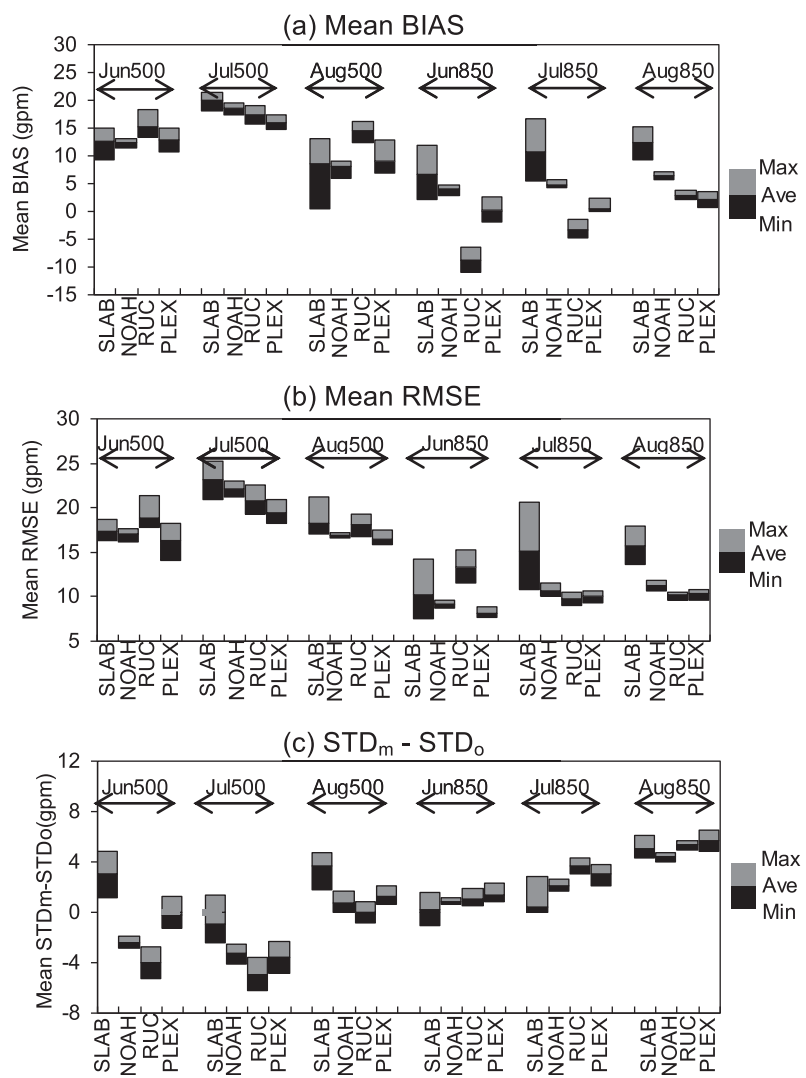

FIG. 8. Ensemble monthly 500- and 850-hPa results of (a) BIAS, (b) RMSE, and (c) $\mathrm{STD}_{M}-\mathrm{STD}_{O}$ for $0000 \mathrm{UTC}$, where shaded bars are the same as those shown in Fig. 5.

July, and August, respectively. This clearly indicates that SLAB presents the most apparent monthly variation in the 500-hPa BIAS. Relatively, BIAS changes from the other LSSs are more moderate, with RUC being the most stable. Similarly, large differences appear at $850 \mathrm{hPa}$. In this case, $\mathrm{NOAH}$ results in the BIAS with the least change, while RUC produces the largest variations in BIAS (e.g., the RUC BIAS at 0000 UTC changes from $-9.8 \mathrm{gpm}$ in June to $2.2 \mathrm{gpm}$ in August).

\section{c. Comparison of sensitivity: LSSs versus PBLSs}

Because of the substantial influences of boundary layer processes on the climate system, several researchers have emphasized the role of PBL on climate. For example, Flaounas et al. (2011) examined the sensitivity of the 2006 West African monsoon simulation to convection and PBL parameterization using WRF, while Solman and Pessacg (2012) performed several 3-month MM5 simulations using different cumulus schemes and PBLSs to define the optimal combination of physical parameterizations over South America. As indicated by Garratt (1993), intercomparisons of PBLSs and LSSs are needed for climate models. In this context, it is useful to compare the relative importance of LSSs and PBLSs in GPH simulations.

We suggest that the comparison should be made between the largest LSS-induced differences and the largest PBLS-induced differences for 500 and $850 \mathrm{hPa}$, separately. Figure 9 presents the seasonal-mean difference fields with the PBLSs (listed in Table 1) at 500 and $850 \mathrm{hPa}$ for $0000 \mathrm{UTC}$. Looking back at the difference fields induced by the LSSs (e.g., Figs. 2, 3), the LSSinduced GPH difference fields are larger than those induced by the PBLSs when considering the total area with large difference values and maximum values. For instance, over most of northwestern China, the 500-hPa RUC-SLAB and ACM2bl-QNSEbl differences both exceed $10 \mathrm{gpm}$, where the LSS-induced differences can be substantially larger (Fig. $2 \mathrm{~g}$ vs Fig. 9c). At $850 \mathrm{hPa}$ over eastern China and in the neighboring areas, the RUC-SLAB and ACM2bl-QNSEbl differences are both greater than $6 \mathrm{gpm}$ where the LSS-induced differences are still much larger (Fig. 3g vs Fig. 9d). Moreover, all of the Student's $t$-test results confirm the larger LSSinduced sensitivity: only two out of six comparisons show statistical significance for $500 \mathrm{hPa}$ (i.e., the ACM2blQNSEbl and YSUbl-QNSEbl differences out of the differences among the four PBLSs), and for $850 \mathrm{hPa}$, no large areas with statistical significance appear for the differences induced by the PBLS.

Considering the results from both the LSSs and PBLSs, the regions with significant differences detected using the Student's $t$ test are generally consistent with and somewhat different from those determined by merely subtracting the ensemble means (e.g., Figs. 2g, 9c). These results suggest that the Student's $t$-test results provide an additional inspection of significant differences and do not contradict the subtraction results (e.g., because of the large variances of the inspected time series, the two time series in the Student's $t$ test might not be significantly different, although their average values are very different).

Similar to the LSS-induced difference fields, the $500-\mathrm{hPa}$ difference fields caused by the PBLSs are generally characterized by a few large-difference regions, such as the region covering the larger part of China for the $500-\mathrm{hPa}$ QNSEbl-ACM2bl differences (Fig. 9c). Additionally, although no significant differences in ensemble mean might be identified, the differences in ensemble maximum and minimum would generally be statistically significant (e.g., Figs. $9 \mathrm{~g}-\mathrm{j}$ ).

Figure 10 presents the ensemble seasonal-mean GPH BIAS and RMSE using different PBLSs. When considering the BIAS and RMSE, the LSS-induced GPH errors are generally equivalent to those induced by the PBLSs (Fig. 5 vs Fig. 10) and the LSS-induced errors are slightly larger at $850 \mathrm{hPa}$. This result is consistent with 
(a) Mean MYJbl-ACM2bl $500 \mathrm{hPa}$

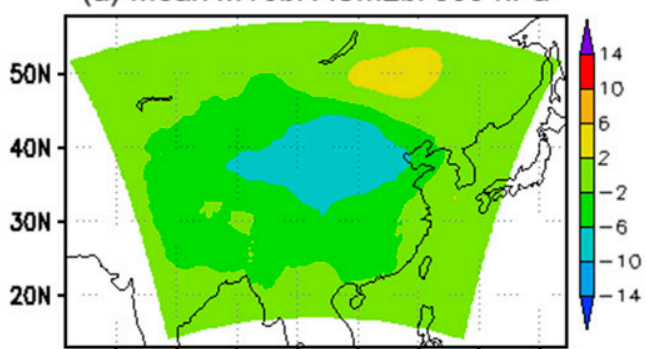

(c) Mean QNSEbl-ACM2bl $500 \mathrm{hPa}$

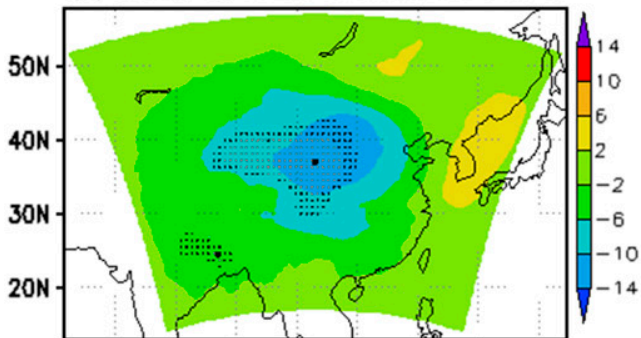

(e) Mean YSUbl-QNSEbl $500 \mathrm{hPa}$

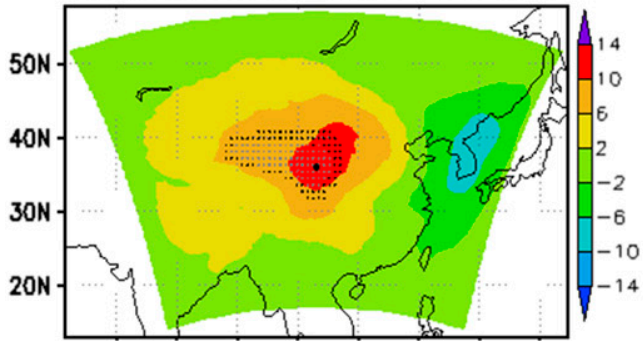

(g) Maximum ACM2bl-QNSEbl $500 \mathrm{hPa}$

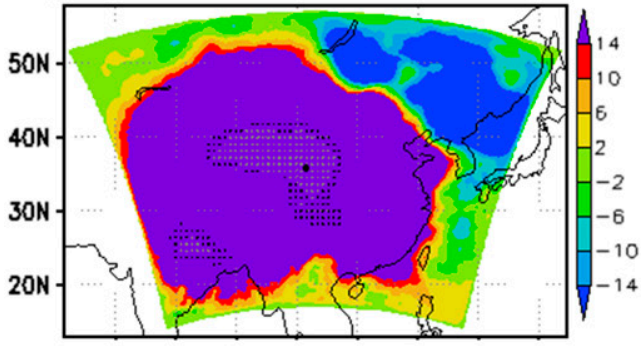

(i) Minimum ACM2bl-QNSEbl $500 \mathrm{hPa}$

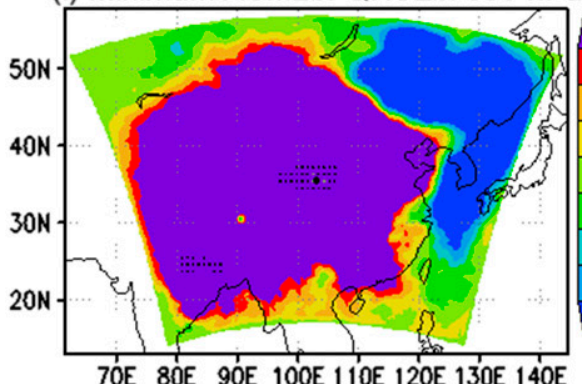

(b) Mean MYJbl-ACM2bl $850 \mathrm{hPa}$

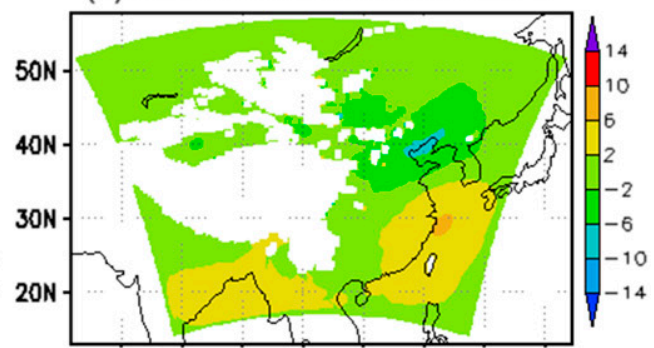

(d) Mean QNSEbl-ACM2bl $850 \mathrm{hPa}$

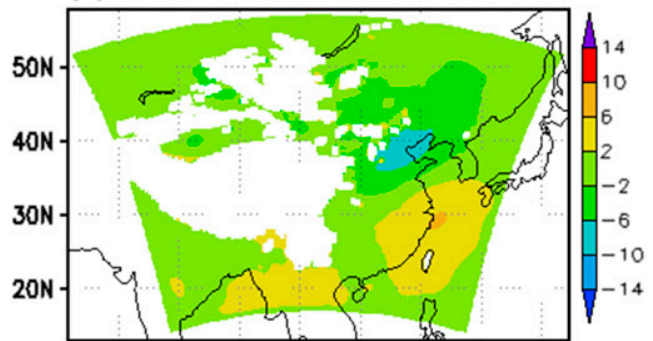

(f) Mean YSUbl-QNSEbl $850 \mathrm{hPa}$

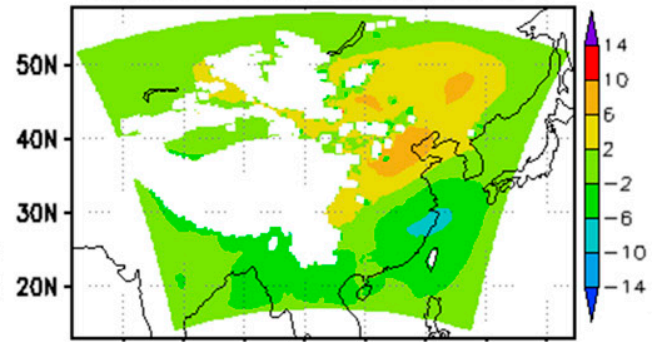

(h) Maximum ACM2bl-QNSEbl $850 \mathrm{hPa}$

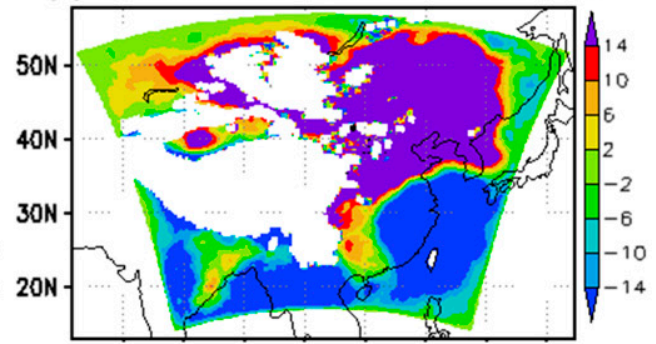

(j) Minimum ACM2bl-QNSEbl $850 \mathrm{hPa}$

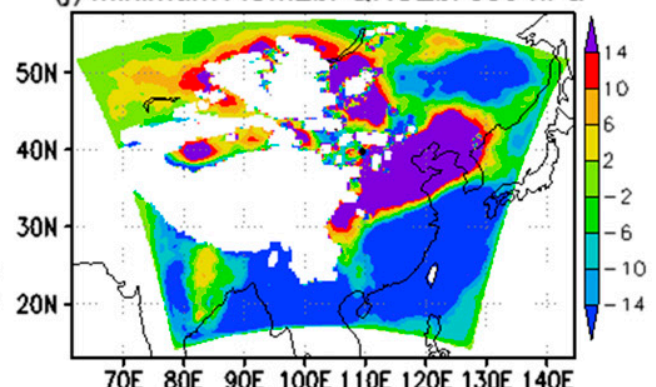

FIG. 9. As in Figs. 2-4, but for PBLS-induced simulations. 

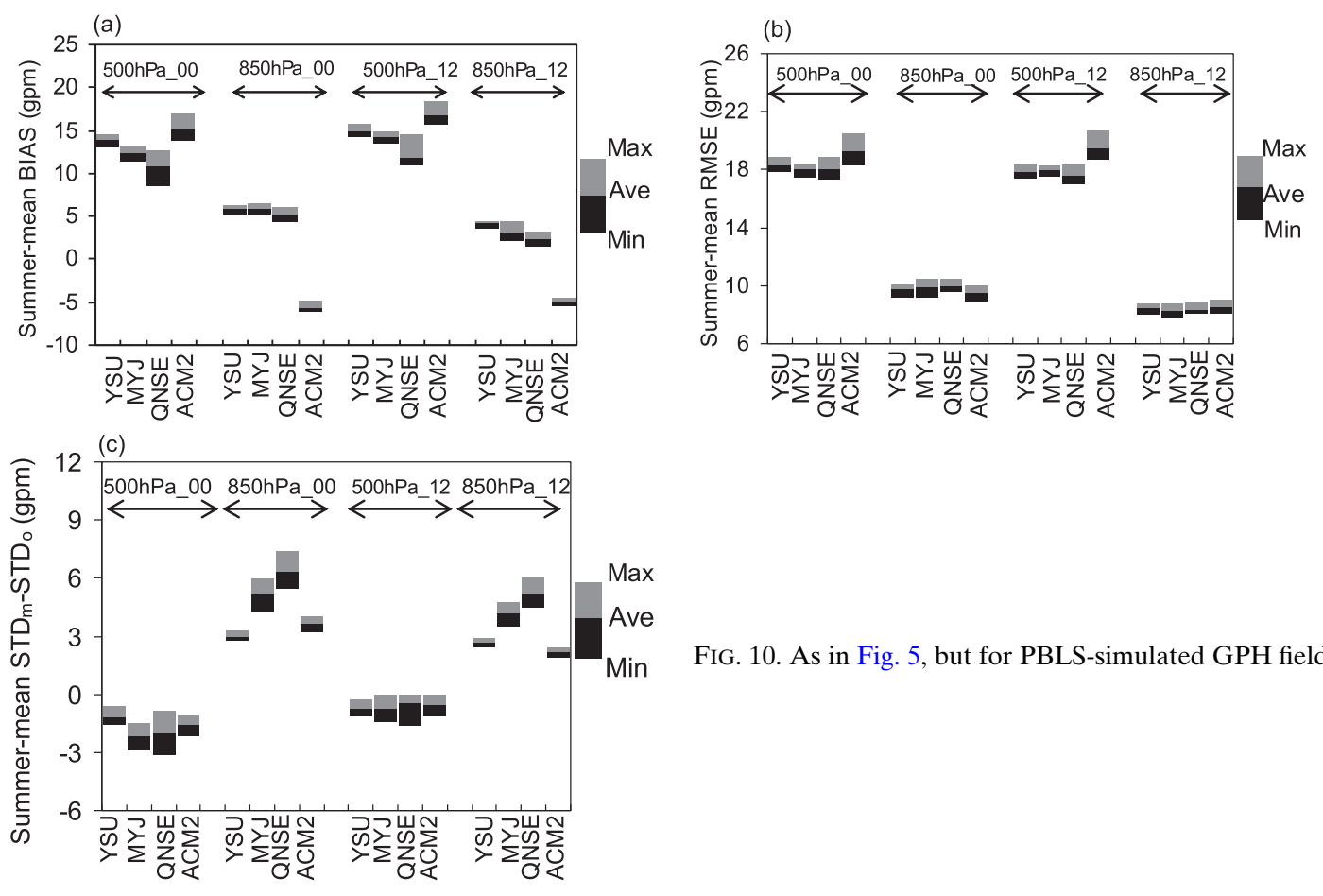

FIG. 10. As in Fig. 5, but for PBLS-simulated GPH fields.

the above-mentioned difference field results. Moreover, the LSS ensemble spread values are generally larger than those of the PBLS simulations, which is consistent with the ranges of the measures, such as BIAS and RMSE (Figs. 5, 10). All of these results demonstrate that the GPH sensitivity to the LSSs is generally equivalent to or above that of the PBLSs, which confirms the importance of the LSS choice when simulating the GPHs of regional climate.

\section{Explanation of GPH change}

The LSSs regulate the GPHs through modifying the surface fluxes. In fact, there are some further intermediate processes between surface energy transfer and the GPHs: land surface fluxes need to take effect by acting on some thermal quantities such as air temperature and pressure via thermodynamical processes in the atmosphere. Therefore, the processes that occur in more interior atmosphere other than surface turbulent transfer are also important in modifying the GPHs.

Figure 11 shows the seasonal-mean differences in sensible heat flux, surface air temperature (SAT), and surface pressure among the SLAB and other schemes for an investigated subarea with relatively low elevation in eastern China (denoted as $D_{\text {ec }}$ in Fig. 1). These results suggest that although higher sensible heat flux does not necessarily result in a higher SAT over different areas from a given LSS ensemble [e.g., over the area $\left(32^{\circ}-\right.$ $\left.34^{\circ} \mathrm{N}, 116^{\circ}-118^{\circ} \mathrm{E}\right)$, the SLAB-simulated higher sensible heat flux corresponds to a lower SAT; Fig. 11a vs Fig. 11e], the increased sensible heat flux resulting from different LSSs generally heats the air directly and results in a generally higher SAT for the study area (e.g., Figs. 11b-d vs Figs. 11f-h, respectively). Meanwhile, at low levels near the land surface, the heated air arises, which results in the horizontal convergence of the air mass over the region. Because of hydrostatic balance, a lower surface air pressure is generally induced into the air column (e.g., Figs. 11j-1). This is consistent with results reported previously; for example, Jerez et al. (2012) investigated the LSS role for climate change projections and indicated that the enhanced warming implies a strengthening of the Iberian thermal low and the cyclonic circulation.

Figure 12 depicts the LSS-induced surface fluxes, air temperature, and air pressure that are associated with the GPH changes for the three investigated subareas (Fig. 1). It shows that although the net radiation at the surface has a slight LSS-induced change, generally, the increase in sensible heat flux corresponds to the decrease in latent heat flux and the SAT is positively correlated with sensible heat flux (Figs. 12a,c,e). Additionally, the SAT is negatively correlated with surface pressure, and the surface pressure is positively correlated with the $850-$ and $500-\mathrm{hPa}$ GPH BIASs (Figs. 12b,d,f), which further suggests that the GPH 
(a) SLAB SH

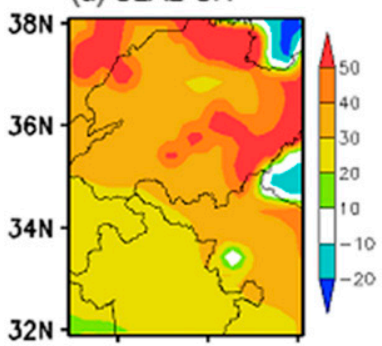

(e) SLAB SAT

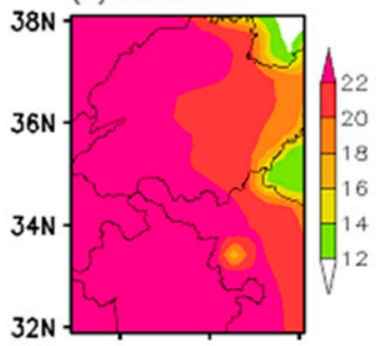

(i) SLAB PSFC

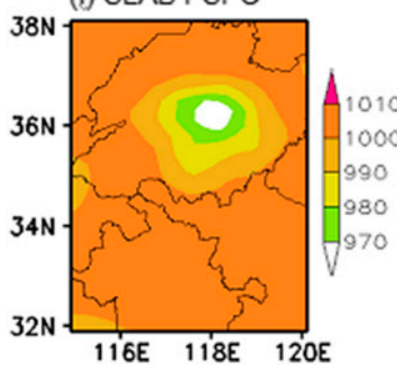

(b) NOAH-SLAB SH

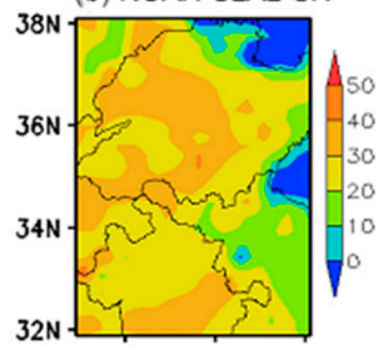

(f) NOAH-SLAB SAT

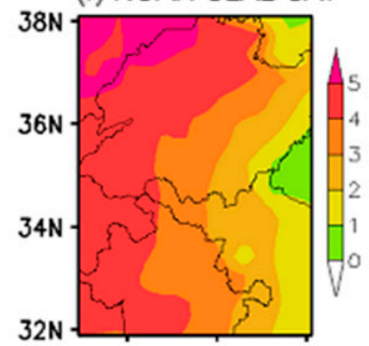

(j) NOAH-SLAB PSFC

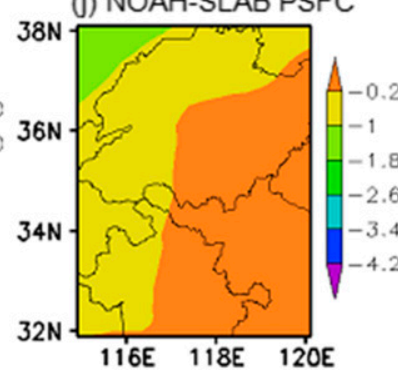

(c) RUC -SLAB SH

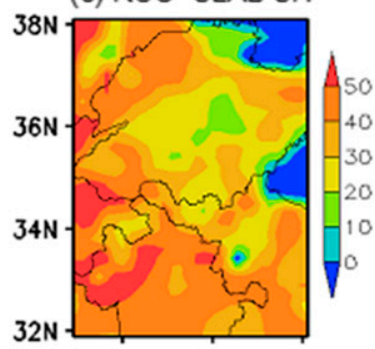

(g) RUC-SLAB SAT

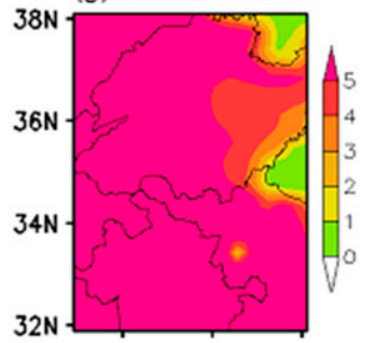

(k) RUC-SLAB PSFC

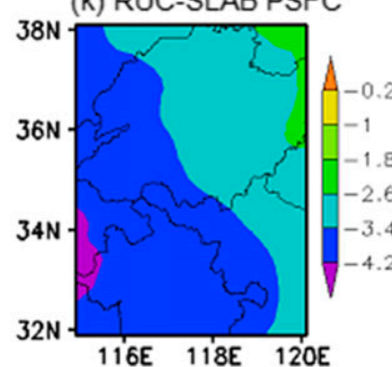

(d) PLEX -SLAB SH

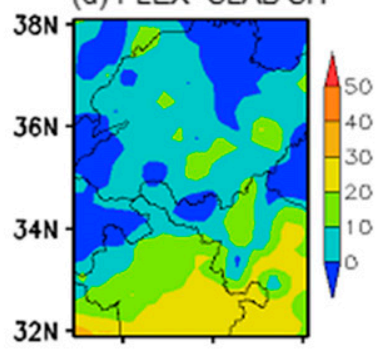

FIG. 11. Ensemble-mean seasonal SLAB means and differences between SLAB and the other LSSs. (a) SLAB sensible heat flux $\left(\mathrm{W} \mathrm{m}^{-2}\right)$. (b) Difference in sensible heat flux between NOAH and SLAB (NOAH - SLAB). (c) As in (b), but for RUC - SLAB. (d) As in (b), but for PLEX - SLAB. (e)-(h) As in (a)-(d), but for SLAB SAT $\left({ }^{\circ} \mathrm{C}\right)$. (i)-(l) As in (a)-(d), but for SLAB surface pressure (hPa).

BIASs are caused by the changes in air temperature and pressure.

Figures $12 \mathrm{~g}$ and $12 \mathrm{~h}$ depict the GPH differences in (13) and (14) between the SLAB and other LSSs due to changes in temperature and pressure and the total LSS-induced GPH difference for the $D_{\text {ec }}$ subarea. All three terms, total difference $D_{h}$, difference due to temperature change $D_{t}$, and difference due to pressure change $D_{p}$, are directly calculated from simulated GPH fields and pressure and temperature fields rather than from (13) and (14). Because the air column has no exchange with the environment, the increase in the lower-level temperature will directly result in an increase in the pressure level (i.e., $D_{h}$ and $D_{t}$ have the same sign). However, at the regional scale, the impact of the environment on the air column cannot be ignored. As shown in Figs. $12 \mathrm{~g}$ and $12 \mathrm{~h}, D_{h}$ and $D_{t}$ have opposite signs, while $D_{h}$ and $D_{p}$ have the same sign.
Thus, the lower atmospheric warming of the regional air column is accompanied by a reduced GPH at the isobaric surface, which plays a leading role in the surface pressure change in modifying the heights of the pressure levels (compared with the secondary role of the temperature change), especially for the 850$\mathrm{hPa}$ level in this study. The GPH differences calculated by the simulation results rather than by (13) and (14) suggest that $D_{h}$ is basically balanced by $D_{t}$ and $D_{p}$, which are consistent with the theoretical results from (13) and (14). At $500 \mathrm{hPa}$ across the region (Fig. $12 \mathrm{~g}$ ), the ensemble-mean $D_{h}$ is less than $5 \mathrm{gpm}$, which shows that the simulated seasonal-mean GPH is not sensitive to the LSS choice. However, at the monthly scale (e.g., July), $D_{h}$ can reach more than $10 \mathrm{gpm}$, which suggests a substantial sensitivity that is much higher than at the seasonal scale. At $850 \mathrm{hPa}$ (Fig. 12h), the seasonal-mean $D_{h}$ reaches approximately 

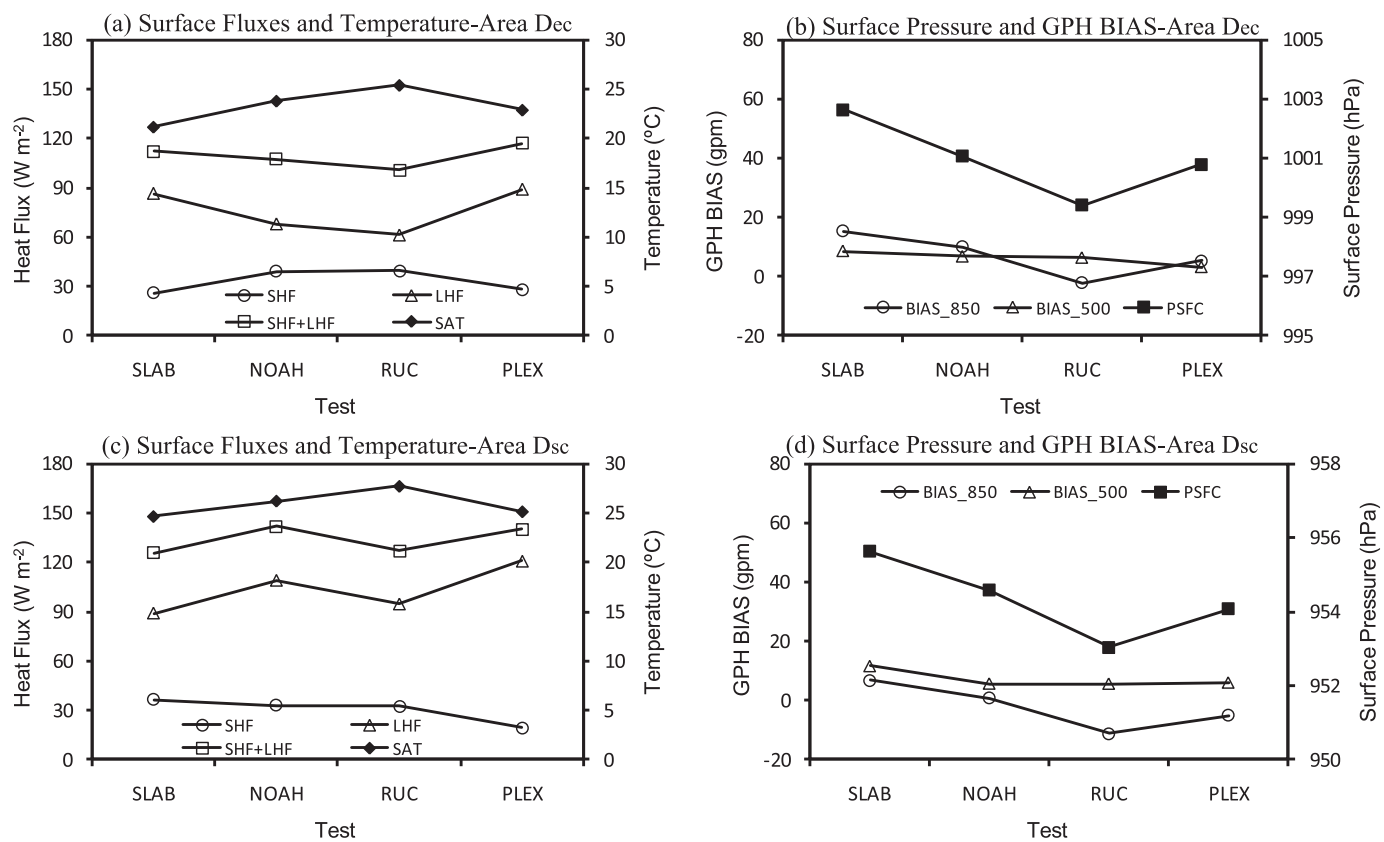

(e) Surface Fluxes and Temperature-Area Dtb
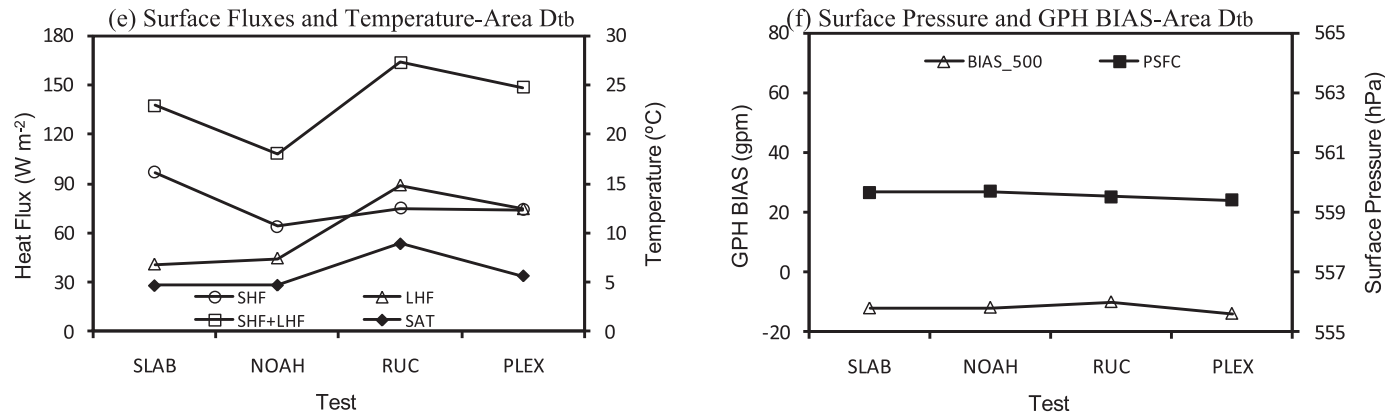

(g) 500-hPa GPH Difference (Dec)
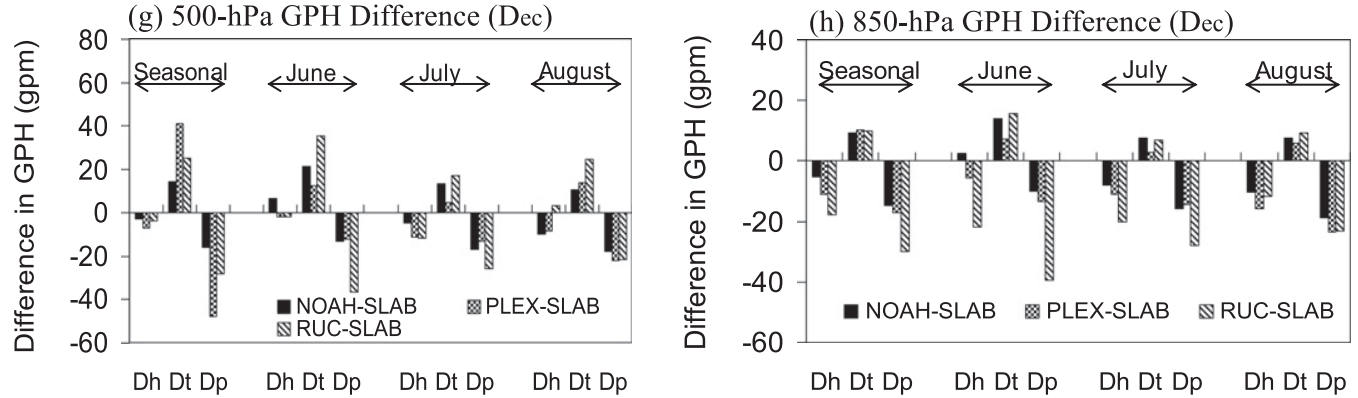

FIG. 12. Ensemble LSS-induced means for the three subareas (Fig. 1): (a) sensible heat flux (SHF), land heat flux (LHF), the sum of SHF and LHF, and SAT for $D_{\mathrm{ec}}$; (b) 850- and 500-hPa GPH BIASs and surface air pressure for $D_{\mathrm{ec}} ;$ (c) as in (a), but for $D_{\mathrm{sc}} ;$ (d) as in (b), but for $D_{\mathrm{sc}} ;$ (e) as in (a), but for $D_{\mathrm{tb}} ;$ (f) as in (b), but for $D_{\mathrm{tb}} ;(\mathrm{g}) 500-\mathrm{hPa}$ GPH differences, where $D_{h}=\delta H_{500}, D_{t}=H_{500} \delta \bar{T} / \bar{T}$, and $D_{p}=1.44 H_{500} \delta p_{s} / p_{s}$; and (h) 850-hPa GPH differences, where $D_{h}=\delta H_{850}, D_{t}=H_{850} \delta \bar{T} / \bar{T}$, and $D_{p}=6.15 H_{850} \delta p_{s} / p_{s}(\mathrm{gpm})$.

$18 \mathrm{gpm}$ and shows a pronounced LSS-induced difference. At the monthly scale (e.g., July), $D_{h}$ exceeds $20 \mathrm{gpm}$, which also displays a higher sensitivity for the $D_{\text {ec }}$ area.

It is noteworthy that (13) and (14) are theoretically derived from the hydrostatic equilibrium equation, which is different from the WRF formulations that use the nonhydrostatic dynamical framework. We suggest the derived equations confirm and explain, theoretically, the GPH changes due to the changes in air temperature and surface pressure over quite a large area (e.g., $D_{\mathrm{ec}}$ ). The reasons are as follows: 
1) The $D_{h}, D_{t}$, and $D_{p}$ are directly calculated from simulated GPH fields, and there is a good balance among the three terms. This confirms our derived equations quantitatively. Additionally, it suggests that although the WRF uses the nonhydrostatic dynamical framework, over quite a large area (e.g., $D_{\text {ec }}$ ), the hydrostatic equilibrium equation is still satisfied.

2) The balance of the three terms suggests qualitatively that the LSS-induced GPH changes are caused by the changes in air temperature and surface pressure under the hydrostatic equilibrium over a given area. This is why, generally, the $D_{t}$ and $D_{p}$ terms have opposite signs.

Given that the 850- and 500-hPa BIASs are two special forms of $\delta H_{850}$ and $\delta H_{500}$ in (13) and (14), respectively, and that the effect of pressure change on GPH is generally dominant over and opposite to the effect of temperature change (Figs. 12g,h), the coefficient (i.e., $6.15 H_{850}$ ) of the pressure-change term on the right-hand side of $(13)$ is generally larger than that (i.e., $\left.1.44 H_{500}\right)$ of (14), which suggests that the amplitude of the $850-\mathrm{hPa}$ BIAS is generally larger than that at $500 \mathrm{hPa}$ for localized regions (Fig. 5c).

Compared with latent heat flux, sensible heat flux more directly heats the SAT, affects surface pressure, and hence more directly leads to the GPH changes. However, latent heat flux is also important because of the following reasons:

1) Given a certain net radiation at the surface, the amount of the net radiation is basically partitioned between sensible and heat fluxes. Latent heat flux then acts on the GPH via sensible heat flux in the partitioning, and in this context, the effect of latent heat flux is equivalent to the effect of sensible heat flux on the GPH.

2) Latent heat flux means evapotranspiration from the land surface becomes a portion of water vapor in the atmosphere and can change surface net radiation because of the effect of the greenhouse gas. In addition, the added water vapor can also condense in the atmosphere (e.g., via convection), release latent heat, and further change the atmospheric state. However, because the LSS-induced change in water vapor contributes little to the total precipitable water, the effect induced by the greenhouse gas and the latent heat release is suggested to be minor compared to the first reason.

Note that latent heat flux is highly relevant to soil moisture (e.g., latent heat flux is proportional to evapotranspiration, and the evapotranspiration difference between PXsm and PLEX is shown in Fig. 5). We suggest that soil moisture also plays an important role in the GPH change for areas with a humid or semihumid climate (e.g., the climate transient zone of northern China); however, in areas with an arid climate (e.g., the deserts that widely cover northwestern China), latent heat flux (and soil moisture) has little effect on the GPH.

Considering that at the land surface the net surface radiation is basically partitioned between latent and sensible heat fluxes, both latent and sensible heat fluxes are equally important, whereas in the lower troposphere, sensible heat flux directly affects the SAT (and hence pressure) while latent heat flux shows little effect, as is explained in the equation for SAT change (Zeng et al. 2014, 2015). Additionally, because the GPH is an atmospheric parameter that land surface processes can act on indirectly, we can conclude that, generally, the LSS-induced change in sensible heat flux is mainly responsible for the LSS-induced GPH sensitivity via affecting air temperature and pressure.

\section{Summary and discussion}

In this paper, we investigated the effects of the land surface schemes (LSSs) on simulated geopotential heights (GPHs) over continental China during the summer of 2003 using the 12-member ensembles with ARW, version 3 . Although the model can generally reproduce the GPH patterns over China, the simulated GPH fields are sensitive to the coupled-model ensembles using different LSSs.

At the seasonal scale, obvious systematic distribution differences occur between different LSS-ensemble GPHs, which indicate that the simulated GPHs are sensitive to different LSS ensembles over continental China. Particularly, 500-hPa GPH differences of more than $10 \mathrm{gpm}$ between the ensemble means (e.g., the RUC-SLAB mean difference) occurred over northwestern China. These differences potentially occurred because northwestern China is located in a dry climate region where lower soil thermal inertia values exist; thus, LSS-induced perturbed atmospheric conditions would have a larger impact on the land surface than elsewhere, and the land surface would amplify the GPH changes in the region. These differences can be very large compared with the multiyear GPH anomalies given by Shabbar et al. (1990) and the forecast errors provided by $\mathrm{Xu}$ et al. (2001). Because of the slowly varying nature of GPH, the LSS-induced 500-hPa GPH difference fields are generally characterized by two large areas with opposite signs over continental China and its surrounding regions.

At $850 \mathrm{hPa}$, the sensitivity of simulated GPH to different LSS ensembles is found to be higher than that of 500-hPa GPH because the LSS choice largely influences the simulated GPH fields directly by modifying surface 
fluxes in the lower atmosphere rather than in the upper atmosphere. Among the four LSS ensembles, RUCsimulated GPHs significantly change with the pressure level.

It appears that simulated monthly GPHs are more sensitive to the LSS choice than simulated seasonal GPHs. Even if the ensemble-mean seasonal spatial variability of GPH is only slightly sensitive to the LSS choice, the spatial variability shows quite high sensitivity at the monthly scale.

Considering the overall behavior of the measures, PLEX behaved the best, followed by NOAH, RUC, and SLAB for the GPH simulations. Although large LSSinduced differences appear, the largest difference generally exists between SLAB and other schemes, which demonstrates that more detailed parameterizations in soil moisture and vegetation physiology are needed. Additionally, good performance of the coupled model in simulating surface fluxes may not necessarily result in a good GPH simulation. All of these suggest the complexity of the land-atmosphere coupled-model performances and the need to improve both the land and the atmospheric components of the model.

The GPH sensitivity to the LSS choice is shown to be generally equivalent to or higher than the sensitivity to the PBLSs, particularly at $850 \mathrm{hPa}$. Previous studies have demonstrated that the PBLSs can significantly affect the model climatology, including precipitation, temperature, and moisture (e.g., Giorgi et al. 1993). This study demonstrates the substantial impacts of different LSSs and PBLSs on GPH climatology simulations.

The result of soil-moisture-induced differences implies that refining the LSS parameterizations should be the first step rather than land initializations for state-ofthe-art LSSs (given the land-cover types) when coupledmodel simulations are performed, for example, for LSS studies during the second phase of GLACE.

Different LSS choice can result in large simulated GPH differences, which mainly result from different surface sensible heat fluxes induced by different LSSs, thereby causing further surface pressure and average temperature variations between the pressure levels. The theoretical analysis shows that the LSS-induced GPH change at a given pressure level is balanced by two terms, one based on temperature change and one with the opposite sign and based on surface pressure change, which could dominate the total GPH change. Thus, LSS-enhanced sensible heat leads to higher low-level temperature, which is accompanied by the rise of air, the horizontal convergence of the air mass, and a reduction in the low-level pressure. This result is further confirmed by the ensemble simulation results.

In this study, we focus on the LSS-induced sensitivity of the GPH simulations. In fact, state-of-the-art LSSs are generally very sophisticated in complexity, and many factors may contribute to model (both coupled and offline) errors. For example, Koster et al. (2004) highlighted the importance of soil moisture in land-atmosphere coupling over some "hot spot" regions in summer; Zeng et al. (2015) showed the sensitivity of simulated SAT to initial soil moisture, which is comparable with the sensitivity induced by the LSS choice in the mediumrange weather in eastern China; and Zheng et al. (2012) found a large and cold bias in simulated surface skin temperature over the arid western continental United States during the daytime due to the formulations of roughness lengths. In this paper, we have paid less attention to what causes model biases except for soil moisture. The experiments of this study are performed using nearly the same model area settings and lateralboundary conditions, and the effects of the different LSSs on the simulated GPHs are generally associated with the domain size, spatial resolutions, and physical options of the models (e.g., Marsigli et al. 2014), which suggest some uncertainty of the results in the present regional model study. Additional experiments should be designed to further test the model performance and determine the effects of different LSS choice on GPH simulation.

Notably, the results of the coupled-model ensemble simulations might not reasonably reflect the offline LSS performances. However, the coupled-model simulations would, more or less, produce some features of each LSS as the land component of the coupled model (e.g., Zeng et al. 2015). This study presents the ensemble results of simulated GPHs, which clearly show systematic features for each LSS ensemble (e.g., the performance in the context of BIAS). These features may help modelers (meteorologists) in GPH simulations (forecasts) by choosing a proper LSS. Because these LSS simulations are performed using the coupled mode, the results also suggest the deficiencies in the coupling strategy or the offline LSS behavior (e.g., few offline LSS simulations had been conducted for validation against observations over a large area with a broad range of land-cover types before the LSSs were incorporated into the WRF), which are left for further investigations. Additionally, the BIASs at $500 \mathrm{hPa}$ indicate the overall GPH overestimation for all of the LSSs, which implies that the deficiency may probably lie in the atmospheric (rather than land surface) component of the WRF and that adequate validation for the atmospheric component is also needed before land-atmosphere coupling for the modeling system.

Acknowledgments. This work was supported by the National Natural Science Foundation of China (Grants 41275012 and 41205073). The authors thank three anonymous 
reviewers for their helpful comments on the manuscript, and Dr. J. P. Evans at University of New South Wales, Australia, and Dr. W. Zheng at NOAA for their help in using the MODIS data for relevant simulations.

\section{REFERENCES}

Akkermans, T., W. Thiery, and N. P. M. Van Lipzig, 2014: The regional climate impact of a realistic future deforestation scenario in the Congo basin. J. Climate, 27, 2714-2734, doi:10.1175/JCLI-D-13-00361.1.

Argüeso, D., J. M. Hidalgo-Muñoz, S. R. Gámiz-Fortis, M. J. Esteban-Parra, J. Dudhia, and Y. Castro-Díez, 2011: Evaluation of WRF parameterizations for climate studies over southern Spain using a multistep regionalization. J. Climate, 24, 5633-5651, doi:10.1175/JCLI-D-11-00073.1.

Chen, F., and J. Dudhia, 2001: Coupling an advanced land surfacehydrology model with the Penn State-NCAR MM5 modelling system. Part I: Model implementation and sensitivity. Mon. Wea. Rev., 129, 569-585, doi:10.1175/1520-0493(2001)129<0569: CAALSH $>2.0 . \mathrm{CO} ; 2$

_ , and Z. Xie, 2012: Effects of crop growth and development on regional climate: A case study over East Asian monsoon area Climate Dyn., 38, 2291-2305, doi:10.1007/s00382-011-1125-y.

Chen, H., T. Zhou, R. B. Neale, X. Wu, and G. J. Zhang, 2010: Performance of the New NCAR CAM3.5 in East Asian summer monsoon simulations: Sensitivity to modifications of the convection scheme. J. Climate, 23, 3657-3675, doi:10.1175/ 2010JCLI3022.1.

Chessa, P. A., and F. Lalaurette, 2001: Verification of the ECMWF Ensemble Prediction System forecasts: A study of largescale patterns. Wea. Forecasting, 16, 611-619, doi:10.1175/ 1520-0434(2001)016<0611:VOTEEP > 2.0.CO;2.

Crétat, J., B. Pohl, Y. Richard, and P. Drobinski, 2012: Uncertainties in simulating regional climate of southern Africa: Sensitivity to physical parameterizations using WRF. Climate Dyn., 38, 613-634, doi:10.1007/s00382-011-1055-8.

Dickinson, R., R. Errico, F. Giorgi, and G. Bates, 1989: A regional climate model for the western United States. Climatic Change, 15, 383-422, doi:10.1007/BF00240465.

Ding, Y., and J. C. L. Chan, 2005: The East Asian summer monsoon: An overview. Meteor. Atmos. Phys., 89, 117-142, doi:10.1007/s00703-005-0125-z

Dudhia, J., 1989: Numerical study of convection observed during the winter monsoon experiment using a mesoscale twodimensional model. J. Atmos. Sci., 46, 3077-3107, doi:10.1175/ 1520-0469(1989)046<3077:NSOCOD >2.0.CO;2.

_, 1996 : A multi-layer soil temperature model for MM5. Preprints, Sixth PSU/NCAR Mesoscale Model Users' Workshop, Boulder, CO, NCAR, 49-50. [Available online at https://www. researchgate.net/publication/259865197_A_Multi-layer_Soil_ Temperature_Model_for_MM5.]

Ek, M. B., K. E. Mitchell, Y. Lin, E. Rogers, P. Grunmann, V. Koren, G. Gayno, and J. D. Tarpley, 2003: Implementation of Noah land surface model advances in the National Centers for Environmental Prediction operational mesoscale Eta Model. J. Geophys. Res., 108, 8851, doi:10.1029/2002JD003296.

Findell, K. L., T. R. Knutson, and P. C. D. Milly, 2006: Weak simulated extratropical responses to complete tropical deforestation. J. Climate, 19, 2835-2850, doi:10.1175/JCLI3737.1.

Flaounas, E., S. Bastin, and S. Janicot, 2011: Regional climate modelling of the 2006 West African monsoon: Sensitivity to convection and planetary boundary layer parameterization using WRF. Climate Dyn., 36, 1083-1105, doi:10.1007/ s00382-010-0785-3.

Garratt, J. R., 1993: Sensitivity of climate simulations to land-surface and atmospheric boundary-layer treatments-A review. J. Climate, 6, 419-448, doi:10.1175/1520-0442(1993)006<0419: SOCSTL $>2.0 . C O ; 2$.

Giorgi, F., 1991: Sensitivity of simulated summertime precipitation over the western United States to different physics parameterizations. Mon. Wea. Rev., 119, 2870-2888, doi:10.1175/ 1520-0493(1991)119<2870:SOSSPO > 2.0.CO;2.

- and M. R. Marinucci, 1991: Validation of a regional atmospheric model over Europe: Sensitivity of wintertime and summertime simulations to selected physics parameterizations and lower boundary conditions. Quart. J. Roy. Meteor. Soc., 117, 1171-1207, doi:10.1002/qj.49711750204.

— Regional climate modelling revisited. J. Geophys. Res., 104, 6335-6352, doi:10.1029/98JD02072.

— M. R. Marinucci, and G. T. Bates, 1993: Development of a second-generation Regional Climate Model (RegCM2). Part I: Boundary-layer and radiative transfer processes. Mon. Wea. Rev., 121, 2794-2813, doi:10.1175/1520-0493(1993)121<2794: DOASGR $>2.0 . \mathrm{CO} ; 2$.

Gochis, D. J., W. J. Shuttleworth, and Z. L. Yang, 2002: Sensitivity of the modeled North American monsoon regional climate to convective parameterization. Mon. Wea. Rev., 130, 1282-1298, doi:10.1175/1520-0493(2002)130<1282:SOTMNA > 2.0.CO;2.

Guo, Z., P. A. Dirmeyer, and T. DelSole, 2011: Land surface impacts on subseasonal and seasonal predictability. Geophys. Res. Lett., 38, L24812, doi:10.1029/2011GL049945.

Gutman, G., and A. Ignatov, 1998: The derivation of the green vegetation fraction from NOAA/AVHRR data for use in numerical weather prediction models. Int. J. Remote Sens., 19, 1533-1543, doi:10.1080/014311698215333.

Hong, S. Y., and J.-O. J. Lim, 2006: The WRF single-moment 6-class microphysics scheme (WSM6). J. Korean Meteor. Soc., 42, 129-151.

—_, J. Dudhia, and S. H. Chen, 2004: A revised approach to ice microphysical processes for the bulk parameterization of clouds and precipitation. Mon. Wea. Rev., 132, 103-120, doi:10.1175/1520-0493(2004)132<0103: ARATIM $>2.0 . \mathrm{CO} ; 2$.

_, Y. Noh, and J. Dudhia, 2006: A new vertical diffusion package with explicit treatment of entrainment processes. Mon. Wea. Rev., 134, 2318-2341, doi:10.1175/MWR3199.1.

Janjić, Z. I., 2001: Nonsingular implementation of the MellorYamada level 2.5 scheme in the NCEP Meso Model. NOAA/ NWS/NCEP Office Note 437, NOAA Science Center, 66 pp. [Available online at http://www.emc.ncep.noaa.gov/officenotes/ newernotes/on437.pdf.]

Jerez, S., J. P. Montavez, J. J. Gomez-Navarro, P. A. Jimenez, P. Jimenez-Guerrero, R. Lorente, and J. F. Gonzalez-Rouco, 2012: The role of the land-surface model for climate change projections over the Iberian Peninsula. J. Geophys. Res., 117, D01109, doi:10.1029/2011JD016576.

- - - P. Jimenez-Guerrero, J. J. Gomez-Navarro, R. Lorente-Plazas, and E. Zorita, 2013: A multi-physics ensemble of present-day climate regional simulations over the Iberian Peninsula. Climate Dyn., 40, 3023-3046, doi:10.1007/ s00382-012-1539-1.

Jiang, L., and Coauthors, 2010: Real-time weekly global green vegetation fraction derived from advanced very high resolution 
radiometer-based NOAA operational global vegetation index (GVI) system. J. Geophys. Res., 115, D11114, doi:10.1029/ 2009JD013204.

Kain, J. S., 2004: The Kain-Fritsch convective parameterization: An update. J. Appl. Meteor., 43, 170-181, doi:10.1175/ 1520-0450(2004)043<0170:TKCPAU>2.0.CO;2.

Kanamitsu, M., 1989: Description of the NMC Global Data Assimilation and Forecast System. Wea. Forecasting, 4, 335-342, doi:10.1175/1520-0434(1989)004<0335:DOTNGD>2.0.CO;2.

- and Coauthors, 2002: NCEP Dynamical Seasonal Forecast System 2000. Bull. Amer. Meteor. Soc., 83, 1019-1037, doi:10.1175/ 1520-0477(2002)083<1019:NDSFS > 2.3.CO;2.

Koster, R. D., and Coauthors, 2004: Regions of strong coupling between soil moisture and precipitation. Science, 305, 11381141, doi:10.1126/science.1100217.

Lau, K. M., and S. Yang, 1997: Climatology and interannual variability of the Southeast Asian monsoon. Adv. Atmos. Sci., 14, 141-162, doi:10.1007/s00376-997-0016-y.

Marsigli, C., A. Montani, and T. Paccagnella, 2014: Perturbation of initial and boundary conditions for a limited-area ensemble: Multi-model versus single-model approach. Quart. J. Roy. Meteor. Soc., 140, 197-208, doi:10.1002/qj.2128.

Mellor, G. L., and T. Yamada, 1982: Development of a turbulence closure model for geophysical fluid problems. Rev. Geophys., 20, 851-875, doi:10.1029/RG020i004p00851.

Meng, X. H., J. P. Evans, and M. F. McCabe, 2014: The influence of inter-annually varying albedo on regional climate and drought. Climate Dyn., 42, 787-803, doi:10.1007/ s00382-013-1790-0.

Miralles, D. G., and Coauthors, 2013: El Niño-La Niña cycle and recent trends in continental evaporation. Nat. Climate Change, 4, 122-126, doi:10.1038/nclimate2068.

Mlawer, E. J., S. J. Taubman, P. D. Brown, M. J. Iacono, and S. A. Clough, 1997: Radiative transfer for inhomogeneous atmosphere: RRTM, a validated correlated- $k$ model for the longwave. J. Geophys. Res., 102, 16 663-16682, doi:10.1029/97JD00237.

Phillips, N. A., 1957: A coordinate system having some special advantages for numerical forecasting. J. Meteor., 14, 184-185, doi:10.1175/1520-0469(1957)014<0184:ACSHSS >2.0.CO;2.

Pleim, J. E., 2007: A combined local and nonlocal closure model for the atmospheric boundary layer. Part I: Model description and testing. J. Appl. Meteor. Climatol., 46, 1383-1395, doi:10.1175/ JAM2539.1.

Reichler, T., and J. O. Roads, 2004: Time-space distribution of long-range atmospheric predictability. J. Atmos. Sci., 61, 249-263, doi:10.1175/1520-0469(2004)061<0249:TDOLAP>2.0.CO;2.

Saha, S., and Coauthors, 2006: The NCEP Climate Forecast System. J. Climate, 19, 3483-3517, doi:10.1175/JCLI3812.1.

Seneviratne, S. I., D. Lüthi, M. Litschi, and C. Schär, 2006: Landatmosphere coupling and climate change in Europe. Nature, 443, 205-209, doi:10.1038/nature05095.

Shabbar, A., K. Higuchi, and J. L. Knox, 1990: Regional analysis of Northern Hemisphere $50 \mathrm{kPa}$ geopotential heights from 1946 to 1985. J. Climate, 3, 543-557, doi:10.1175/ 1520-0442(1990)003<0543:RAONHK $>2.0 . \mathrm{CO} ; 2$.

Shukla, J., and Y. Mintz, 1982: Influence of the land-surface evapotransporation on the earth's climate. Science, 215, 1498-1501, doi:10.1126/science.215.4539.1498.

Skamarock, W. C., and Coauthors, 2008: A description of the Advanced Research WRF version 3. NCAR Tech. Note NCAR/TN-4751STR, 125 pp., doi:10.5065/D68S4MVH.

Smirnova, T. G., J. M. Brown, and S. G. Benjamin, 1997: Performance of different soil model configurations in simulating ground surface temperature and surface fluxes. Mon. Wea. Rev., 125, 1870-1884, doi:10.1175/1520-0493(1997)125<1870:PODSMC>2.0.CO;2.

,,--- , and D. Kim, 2000: Parameterization of coldseason processes in the MAPS land surface scheme. J. Geophys. Res., 105, 4077-4086, doi:10.1029/1999JD901047.

Solman, S. A., and N. L. Pessacg, 2012: Regional climate simulations over South America: Sensitivity to model physics and to the treatment of lateral boundary conditions using the MM5 model. Climate Dyn., 38, 281-300, doi:10.1007/ s00382-011-1049-6.

Sukoriansky, S., B. Galperin, and V. Perov, 2006: A quasi-normal scale elimination model of turbulence and its application to stably stratified flows. Nonlinear Processes Geophys., 13, 9-22, doi:10.5194/npg-13-9-2006.

Walther, A., J. H. Jeong, G. Nikulin, C. Jones, and D. Chen, 2013: Evaluation of the warm season diurnal cycle of precipitation over Sweden simulated by the Rossby Centre regional climate model RCA3. Atmos. Res., 119, 131-139, doi:10.1016/ j.atmosres.2011.10.012.

Wang, B., and H. Lin, 2002: Rainy season of the Asian-Pacific summer monsoon. J. Climate, 15, 386-396, doi:10.1175/ 1520-0442(2002)015<0386:RSOTAP $>2.0 . C O ; 2$.

Wang, Y., L. R. Leung, J. L. McGregor, D. K. Lee, W. C. Wang, Y. H. Ding, and F. Kimura, 2004: Regional climate modelling: Progress, challenges and prospects. J. Meteor. Soc. Japan, $\mathbf{8 2}$, 1599-1628, doi:10.2151/jmsj.82.1599.

Wu, R., and B. Wang, 2001: Multi-stage onset of the summer monsoon over the western North Pacific. Climate Dyn., 17, 277-289, doi:10.1007/s003820000118.

Xiu, A., and J. E. Pleim, 2001: Development of a land surface model. Part I: Application in a mesoscale meteorological model. J. Appl. Meteor., 40, 192-209, doi:10.1175/ 1520-0450(2001)040<0192:DOALSM > 2.0.CO;2.

Xu, Q., L. Wei, A. V. Tuyl, and E. H. Barker, 2001: Estimation of three-dimensional error covariances. Part I: Analysis of height innovation vectors. Mon. Wea. Rev., 129, 2126-2135, doi:10.1175/ 1520-0493(2001)129<2126:EOTDEC > 2.0.CO;2.

Xue, Y., 1997: Biosphere feedback on regional climate in tropical North Africa. Quart. J. Roy. Meteor. Soc., 123, 1483-1515, doi:10.1002/qj.49712354203.

Yang, T., H. Li, W. Wang, C. Y. Xu, and Z. Yu, 2012: Statistical downscaling of extreme daily precipitation, evaporation, and temperature and construction of future scenarios. Hydrol. Processes, 26, 3510-3523, doi:10.1002/hyp.8427.

Zeng, X.-M., M. Zhao, B. K. Su, J. P. Tang, Y. Q. Zheng, Y. J Zhang, and J. Chen, 2003: Effects of the land-surface heterogeneities in temperature and moisture from the "combined approach" on regional climate: A sensitivity study. Global Planet. Change, 37, 247-263, doi:10.1016/S0921-8181(02)00209-6. , Z. H. Wu, S. Song, S. Y. Xiong, Y. Q. Zheng, Z. G. Zhou, and H. Q. Liu, 2012: Effects of different land surface schemes on the simulation of a heavy rainfall event by WRF. Chin. J. Geophys., 55, 394-408, doi:10.1002/cjg2.1734.

—, B. Wang, Y. Zhang, S. Song, X. Huang, Y. Zheng, C. Chen, and G. Wang, 2014: Sensitivity of high-temperature weather to initial soil moisture: A case study using the WRF Model. Atmos. Chem. Phys., 14, 9623-9639, doi:10.5194/ acp-14-9623-2014.

_- N. Wang, Y. Wang, Y. Zheng, Z. Zhou, G. Wang, C. Chen, and H. Liu, 2015: WRF simulated sensitivity to land surface schemes in short and medium ranges for a high-temperature event in east China: A comparative study. J. Adv. Model. Earth Syst., 7, 1305-1325, doi:10.1002/2015MS000440. 
Zhang, W.-J., T.-J. Zhou, and R.-C. Yu, 2008: Spatial distribution and temporal variation of soil moisture over China. Part I: Multi-data intercomparison. Chin. J. Atmos. Sci., 32, 581-597.

Zhang, Z., J. C. L. Chan, and Y. Ding, 2004: Characteristics, evolution and mechanisms of the summer monsoon onset over Southeast Asia. Int. J. Climatol., 24, 1461-1482, doi:10.1002/joc.1082.

Zheng, W., H. Wei, Z. Wang, X. Zeng, J. Meng, M. Ek, K. Mitchell, and J. Derber, 2012: Improvement of daytime land surface skin temperature over arid regions in the NCEP GFS model and its impact on satellite data assimilation. J. Geophys. Res., 117, D06117, doi:10.1029/2011JD015901.

Zheng, X., and C. S. Frederiksen, 2007: Statistical prediction of seasonal mean Southern Hemisphere 500-hPa geopotential heights. J. Climate, 20, 2791-2809, doi:10.1175/JCLI4180.1.

Zhuang, Z., J. Xue, S. Zhuang, and G. Zhu, 2006: A study of the statistical analysis of the geopotential height background errors in the data assimilation (in Chinese with English abstract). Chin. J. Atmos. Sci., 30, 533-544. 